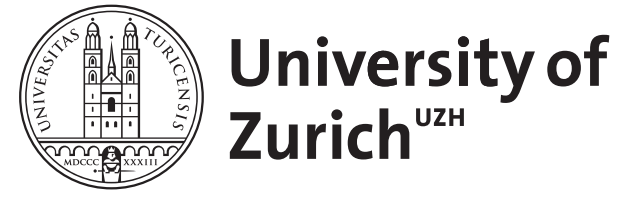

Zurich Open Repository and Archive

University of Zurich

University Library

Strickhofstrasse 39

CH-8057 Zurich

www.zora.uzh.ch

Year: 1985

\title{
Die chronologischen Daten des Ezechielbuches
}

Kutsch, Ernst

Posted at the Zurich Open Repository and Archive, University of Zurich

ZORA URL: https://doi.org/10.5167/uzh-149704

Monograph

Published Version

Originally published at:

Kutsch, Ernst (1985). Die chronologischen Daten des Ezechielbuches. Freiburg, Switzerland / Göttingen, Germany: Universitätsverlag / Vandenhoeck Ruprecht. 


\section{KUTSCH \\ DIE CHRONOLOGISCHEN DATEN \\ DES EZECHIELBUCHES}


Im Auftrag des Biblischen Instituts der Universität

Freiburg Schweiz

des Seminars für biblische Zeitgeschichte

der Universität Münster i. W.

und der Schweizerischen Gesellschaft

für orientalische Altertumswissenschaft

herausgegeben von

Othmar Keel,

unter Mitarbeit von Erich Zenger und Albert de Pury

Ernst Kutsch (geb. 1921) studierte nach Kriegsdienst und Kriegsgefangenschaft 1948-1953 in Mainz evangelische Theologie. Von 1953-1954 war er Repetent für Altes Testament in Mainz, von 1954-1957 als wissenschaftlicher Redakteur für die 3. Auflage des Handwörterbuchs für Theologie und Religionswissenschaft «Die Religion in Geschichte und Gegenwart » in Tübingen tätig; 1955 promovierte er in Mainz bei Friedrich Horst zum Dr. theol. 1957 wurde er dort wissenschaftlicher Assistent, 1960 habilitiert. Von 1963-1966 hatte er in Wien einen Lehrstuhl für Altes Testament und Biblische Archäologie inne und lehrt seit 1966 in Erlangen Alttestamentliche Theologie.

Veröffentlichungen u, a,: Salbung als Rechtsakt im Alten Testament und im Alten Orient, 1963; Sein Leiden und Tod - unser Heil. Eine Exegese von Jesaja 52,13 bis 53,12, 1967; Verheißung und Gesetz. Untersuchungen zum sogenannten «Bund" im Alten Testament, 1973; Neues Testament - Neuer Bund? Eine Fehlübersetzung wird korrigiert, 1978; zahlrciche Aufsätze vornehmlich zu Problemen des Alten und des Neuen Testaments und zur Palästinakunde in Zeitschriften und Festschriften. 
ERNST KUTSCH

\section{DIE CHRONOLOGISCHEN DATEN DES EZECHIELBUCHES}


CIP-Kurztitelaufnabme der Deutschen Bibliothek

Kutsch, Ermst:

Die chronologischen Daten des Ezechielbuches/Ernst Kutsch.

Freiburg (Schweiz): Universitätsverlag

Göttingen: Vandenhoeck und Ruprecht, 1985.

(Orbis biblicus et orientalis; 62)

ISBN 3-7278-0327-4 (Universitätsverlag)

ISBN 3-525-53685-2 (Vandenhoeck und Ruprecht)

NE: GT

(c) 1985 by Universitätsverlag Freiburg Schweiz

Paulusdruckerei Freiburg Schweiz

ISBN 3-7278-0327-4

Digitalisat erstellt durch Florian Lippke, Departement für Biblische Studien, Universität Freiburg Schweiz 
Dem Andenken an

FRIEDRICH BAUMGÄRTEL (1888-1981)

und

LEONHARD ROST (1896-1979)

gewidmet 
VORBEMERKUNG :

Das vorliegende Heft bietet den Text einer Untersuchung, die 1983 in einer Zeitschrift erscheinen sollte, dort aber wegen ihres Umfanges nicht aufgenommen werden konnte. Ich sage Herrn Kollegen Prof. Dr. Othmar Keel verbindlichen Dank dafür, daß er die Veröffentlichung der Arbeit durch ihre Aufnahme in die Reihe "Orbis Biblicus et Orientalis" ermöglicht hat.

Die Literatur wird in den Anmerkungen mit Verfassername und Kurztitel zitiert. Die vollständigen bibliographischen Angaben finden sich in dem Literaturverzeichnis auf $\mathrm{S}$. $77 \mathrm{ff}$. 


\section{INHALTSVERZEICHNIS}

Einleitung 9

I. Das Jahr der Eroberung und Zerstörung Jerusalems 10

II. Die Daten im Buch Ezechiel 33

1. Ez 40,1 33

2. $\operatorname{Ez} 33,21 \quad 41$

3. Ez 1,1-2 45

Exkurs: II Reg 25,27 par. Jer 52,31 55

4. $\operatorname{Ez~8,1~} 59$

5. $\mathrm{Ez} 20,1 \quad 60$

6. $\mathrm{Ez} \mathrm{24,1} 61$

7. Ez 26,1 63

8. $\operatorname{Ez~29,1;30,20;31,1;32,1.17~} 65$

9. Ez 29,17 67

III. Die Ergebnisse $\quad 70$

Tabellen:

I. Zeittafel nach Malamat 72

II. Regierungsjahre des Nebukadnezar $\quad 73$

III. Die verschiedenen Synchronismen 74

IV. Zählung der Jahre in der ausgehenden Königszeit nach Malamat, Vogt, Kutsch 75

$\begin{array}{ll}\text { Literaturverzeichnis } & 77\end{array}$

$\begin{array}{ll}\text { Abkürzungsverzeichnis } & 81\end{array}$ 
Einleitung

Chronologische Probleme, Fragen der Zeitrechnung und der zeitlichen Ansetzung von Ereignissen sind nur scheinbar trockene Angelegenheiten für Spezialisten. Sicher ist es sub specie aeternitatis von geringem Interesse, ob der Tempel in Jerusalem im Sommer des Jahres 587 oder des Jahres 586 zerstört worden ist. Indes: Es ist Sache der wissenschaftlichen Gewissenhaftigkeit, Probleme, die sich von vorgegebenen Texten - für uns: vom Alten Testament - her stellen, soweit wie mit unseren Mitteln und Methoden möglich, einer Klärung zuzuführen. Dies gilt auch für Fragen der Chronologie. So ist es von der Sache her gefordert und legitim, wenn wir im folgenden das Problem der im Ezechielbuch enthaltenen Datenangaben erneut aufnehmen - um so mehr, als wir es einer gegenüber den vorliegenden Behandlungen des Themas weithin neuen Lösung zuführen. Dabei wird sich zeigen, daß von chronologischen Fragestellungen her auch theologische Aussagen des Ezechielbuches in einem neuen Licht erscheinen können.

Ausgangspunkt für die Utbertragung der Daten des Ezechielbuches in unsere Zählung der Jahre "vor Christus" sind die beiden Eroberungen von Jerusalem durch den neubabylonischen König Nebukadnezar II. Die erste Einnahme der Stadt ist durch eine babylonische Chronik auf den 2. Adar des Jahres 598/7, d.h. auf den 16. März 597 fixiert. Umstritten ist dagegen noch immer, ob Jerusalem im Sommer 587 oder 586 zerstört worden ist. Diesem Problem wenden wir uns in Abschnitt I - zum Teil mit neuen weiteren Argumenten - zu. Abschnitt II behandelt dann die Daten im Ezechielbuch, wobei ein Exkurs die beiden hierher gehörenden Texte II Reg 25,27 par. Jer 52,31 einbezieht; und Abschnitt III schließlich gibt eine kurze Zusammenfassung der Ergebnisse. 
I. Das Jahr der Eroberung und Zerstörung Jerusalems

Dreimal im Ezechielbuch ist ein Datum nach den Jahren der Verbannung gegeben: $\operatorname{Ez} 33,21 ; 40,1$ ( $\tau^{e}$ galûtenû "unserer Verbannung") und 1,2 ( $l^{e}$ galût hămmäläk jôjakîn "der Verbannung des Königs Jojachin"); dazu kommt die Ez 1,2 entsprechende Wendung $\imath^{e}$ galut $j^{e} h o \hat{j a k \hat{\imath} n}$ mäläk $j^{e} h \hat{u} d \bar{a}$ "der Verbannung Jojachins, des Königs von Juda," an den beiden parallelen Stellen II Reg 25,27 und Jer 52,31. Da es sich in Ez 1,2; II Reg 25,27; Jer 52,31 um die Verbannung des judäischen Königs Jojachin handelt, ist damit jene Verbannung gemeint, die mit der ersten Einnahme der Stadt Jerusalem durch Nebukadnezar II. gegen Ende des Jahres $598 / 7 \mathrm{v}$. Chr. im Zusammenhang steht. Und da mit "unserer", d.h. der Judäer Verbannung doch wohl an dasselbe Schicksal wie das des Königs Jojachin gedacht ist, hat die Jahreszählung in Ez 33,21 und 40,1 sicher denselben Ausgangspunkt wie an den anderen Stellen. Die übrigen Datierungen im Ezechielbuch - 1,1; 8,1;20,1;24,1;26,1;29,1.17; 30,20; 31,$1 ; 32,1.17$ - sagen nichts darüber aus, von welchem Ausgangspunkt aus, nach welcher "Ära" also die dort genannten Jahre gezählt sind. Die Annahme legt sich nahe, daß auch hier nach der "Verbannung" gerechnet wird; ob sie zutrifft, ist soweit wie möglich für das je einzelne Datum in seinem Verhältnis zu dem durch dieses fixierten Ereignis zu überprüfen.

Die Jahresangaben in alttestamentlichen Daten beziehen sich auf verschiedene "Ären": auf die Regierung bestimmter Könige in Israel, Juda, Babylon, Persien, auf die Verbannung des Königs Jojachin und der mit ihm verschleppten Judäer. Die einzelnen Ären bilden jeweils ein eigenes chronologisches Gerüst; ihre Daten sind dadurch in eine "relative Chronologie" eingegliedert. Aufgabe des Historikers ist es, diese "relative Chronologie" mit der "absoluten Chronologie" unserer Zeitrechnung "ante Christum natum" in Beziehung zu setzen und damit die einzelnen Ereignisse in Jahren "vor Christus" zu fixieren. Für die Übertragung der Daten des Ezechielbuches in Jahre unserer Zeitrechnung ist die genaue Festlegung der beiden Erobe- 
rungen der Stadt Jerusalem durch Nebukadnezar von besonderer Bedeutung. Dazu kommt die Frage, von welchem Jahr an die Jahre "der Verbannung" gezählt werden, welches Jahr das Jahr 1 der Gefangenschaft der Judäer ist.

Die beiden entscheidenden alttestamentlichen Ereignisse, die erste Einnahme Jerusalems sowie die zweite Eroberung der Stadt, die zu ihrer und des salomonischen Tempels Zerstörung geführt hat, sind im Alten Testament in zweifacher Weise festgelegt: durch das Ende der Regierungszeit des jeweils betroffenen judäischen Herrschers und nach den Regierungsjahren des Nebukadnezar. Die Jahre des Babyloniers sind eindeutig in unsere Zeitrechnung anzusetzen: Sein Jahr 1 war das (im Frühjahr wechselnde) Jahr 604/3, sein letztes Jahr, das 43., war das Jahr 562/1. Über die Angaben der Regierungsjahre des Nebukadnezar, die sich im Alten Testament finden, können wir die beiden alttestamentlichen Ereignisse in Jahren unserer Zeitrechnung verankern.

Hier aber liegt nun zugleich eine besondere Schwierigkeit: Für die beiden Eroberungen von Jerusalem macht das Alte Testament hinsichtlich der Jahre des Nebukadnezar unterschiedliche Angaben. Zwar beziffern die alttestamentlichen Texte den zeitlichen Abstand beider Ereignisse einheitlich mit 11 Jahren, sie ordnen sie aber in um jeweils ein Jahr verschiedene Regierungsjahre des Nebukadnezar ein. Welche dieser Angaben historisch richtig ist, ist zu klären. Dabei wird die Datierung der ersten Einnahme von Jerusalem und der Verschleppung des Königs Jojachin in einem neubabylonischen Text wesentliche Hilfe leisten.

Bei den folgenden Auseinandersetzungen gelten vier Voraussetzungen:

1. Die Regierungszeiten, die das Alte Testament für die letzten Könige in Juda angibt, sind richtig überliefert:

$\begin{array}{lrl}\text { für Joahas } & 3 \text { Monate (II Reg 23, 31) } \\ \text { für Jojakim } & 11 \text { Jahre (II Reg 23, 36) } \\ \text { für Jojachin } & 3 \text { Monate (II Reg 24, 8) } \\ \text { für Zedekia } & 11 \text { Jahre (II Reg 24,18). }\end{array}$


2. Wie die Regierungsjahre der babylonischen (und assyrischen) Herrscher sind auch die Jahre dieser judäischen Könige "nachdatierend" gezählt. Das. heißt: Das Jahr, in dem ein König stirbt, wird bei der Zählung der Königsjahre diesem zugerechnet. Das "Jahr 1" des Nachfolgers beginnt mit dem nächsten Neujahr; seine Regierungszeit bis zu diesem Zeitpunkt wird als "Anfang der Regierung" bezeichnet ${ }^{1}$.

3. In Babylonien (wie in Assyrien) wurden die Königsjahre vom Frühjahr an gerechnet; der Monat Nisanu war also der erste Monat.

4. Für die ausgehende Königszeit in Juda stehen (bis jetzt) zwei Synchronismen mit babylonischen Daten zur Verfügung, die je ein Ereignis auf den Tag genau bzw. annähernd auf den Monat genau in unsere Zeitrechnung fixieren. Der (zeitlich) zweite, eine neubabylonische Chronik, die nach ihrem Herausgeber benannte Chronik WISEMAN ${ }^{2}$, datiert die erste Einnahme Jerusalems auf den 2. Adar des 7. Regierungsjahres des Nebukadnezar ${ }^{3}$, das ist der 16. März $597 \mathrm{v}$. Chr. Zeitlich früher liegen babylonische Angaben vor, die - in Kombination mit Aussagen des Alten Testaments - den Tod des Königs Josia in den Sommer des Jahres 609 festlegen. Dies ist hier in Kürze aufzuzeigen.

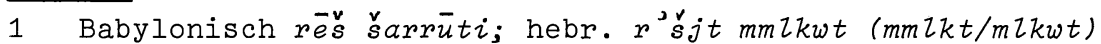
(Jer 26,1;27,1;28,1; 49,34). - Ein instruktives Beispiel für dieses Verfahren bietet Papyrus Nr. 6 bei COWLEY, Aramaic Papyri, 16. Hier ist eine Urkunde folgendermaßen datiert: "Am 18. des Kislev - das ist der 7. Tag des [ägyptischen Monatsl Thot - im Jahr 21, am Anfang der Regierung $\left(r^{\prime} s m l^{r} w t^{2}\right)$, als König Artaxerxes'sich auf seinen Thron setzte." Der "Anfang der Regierung" (nicht das 1. Jahr! gegen COWLEY a.a.0.15) des Artaxerxes fiel in das 21. Jahr seines (hier nicht genannten) bei einer Palastrevolution ermordeten Vaters und Vorgängers Xerxes - es ist das Jahr 465/4 v. Chr. - und ist diesem Jahr noch zugerechnet. Jahr 1 des Artaxerxes begann erst mit dem Neujahr des nächsten Jahres, also im Frühjahr 464 v. Chr. Nach PARKER-DUBBERSTEIN, Babylonian Chronology, 31, fällt der 18. Kislev (=9. Monat) 21 auf den 3. Jan. $464 \mathrm{v}$. Chr.

2 WISEMAN, Chronicles of Chaldaean Kings.

3 B.M. 21946 Rev. 12; WISEMAN, Chronicles, $72 \mathrm{f}$. 
Nach II Reg 23,29 ist Josia in oder bei Megiddo durch den Pharao Necho ums Leben gekommen. Dieser befand sich gerade auf dem Weg "zum (II Reg 23,29: 'al; gemeint ist Jäl) König von Assyrien an den Euphratstrom", nach der - ausführlicheren - Parallelstelle in II Chr 35,20-24: "um bei Karkemisch am Euphrat zu kämpfen". Das "Volk des Landes" in Juda hat nach II Reg 23,30 (= II Chr 36,1) als Nachfolger des Josia - offenbar wegen seiner antiägyptischen Haltung - dessen jüngeren, 23jährigen (V.31 [ $=\mathrm{V} .2]$ ) Sohn Joahas zum König gesalbt ${ }^{4}$. Dieser wurde allerdings bereits nach drei Monaten von dem Pharao Necho in Ribla am Nordende der Biqa ${ }^{c}$, der Talebene zwischen Libanon und Antilibanon, gefangen genommen und durch seinen zwei Jahre älteren Bruder Eljakim ersetzt, den der Ägypter alsbald als Zeichen seiner Abhängigkeit in Jojakim umbenannte (II Reg 23,33f.; II Chr 36,3f.). Was Necho in den zwischen beiden Vorgängen liegenden drei Monaten unternommen hat, berichtet der Teil der babylonischen Chronik - B.M. 21901 -, den GADD im Jahr 1923 herausgegeben hat ${ }^{5}$. Nach Z.66ff. hat ein starkes ägyptisches Heer - ohne Zweifel unter dem hier nicht genannten Necho - in den Monaten Tammuz bis Elul (= 4. bis 6. Monat) des Jahres 609/8 den Assyrer Assur-uballit bei dem - vergeblichen Versuch unterstützt, die stadt Harran den Babyloniern, die sie zusammen mit den Medern im Jahr zuvor erobert hatten, wieder abzunehmen. Wenn Necho im 4. bis 6. Monat in Assyrien war, ist er wohl im 3. Monat an Juda vorbeigezogen; in diese Zeit - d.h. etwa Mai/Juni ${ }^{6}$ - fällt der Tod Josias. Auf seinem Rückweg nach Ägypten im 6. oder 7. Monat hat Necho den Joahas nach Ägypten verschleppt ${ }^{7}$. Durch die Verbindung von alttestamentlichen und

4 Vgl. dazu KUTSCH, Salbung als Rechtsakt, $52 \mathrm{ff.}$, besonders 59; MALAMAT, The Last Kings of Judah, $139 \mathrm{ff.}$, sowie bHorajoth $11 \mathrm{~b}$.

5 GADD, The Fall of Nineveh. - Transkription und Übersetzung dieses Textes finden sich auch bei WISEMAN, Chronicles, $54 \mathrm{ff}$.

6 Vgl. PARKER-DUBBERSTEIN, Babylonian Chronology, 27.

7 Mit diesem Rückmarsch ist - gegen die verbreitete Annahme der Philisterspruch in Jer 47,1-7 nicht in Verbindung zu bringen. Vgl. KUTSCH, "... denn Jahwe vernichtet die Philister", besonders $261 \mathrm{f}$. 
babylonischen Berichten ist der Tod des Josia in den Frühsommer 609 - auf jeden Fall vor den 1. Tischri (= 7. Monat) - datiert.

Wir wenden uns nun zunächst der unterschiedlichen Ansetzung der ersten Einnahme der Stadt Jerusalem im Alten Testament zu. 1. II Reg 24,12 setzt das Ereignis in das 8. Jahr des Nebukadnezar an mit folgendem Bericht (V.10ff.):

(10) $\mathrm{Zu}$ jener Zeit zogen die Leute des Nebukadnezar, des Königs von Babel, gegen Jerusalem herauf; und die Stadt geriet in eine Belagerung. (11) Als nun Nebukadnezar, der König von Babel, die Stadt angriff, während seine Leute sie belagerten, (12) ging Jojachin, der König von Juda, zu dem König von Babel hinaus, er und seine Mutter, seine Hofbeamten, seine Obristen und seine Kämmerer, und der König von Babel nahm ihn gefangen, im 8. Jahr seiner Regierung ${ }^{8}$. (15) Und er führte den Jojachin nach Babel in die Verbannung; auch die Mutter und die Frauen des Königs, seine Kämmerer und die Vornehmen des Landes führte er gefangen yon Jerusalem nach Babel, (16) dazu alle wehrfähigen Leute, 7000, und die Schmiede und Schlosser, 1000, lauter vermögende, kriegstüchtige Männer, die brachte der König von Babel gefangen nach Babel. (17) Und der König von Babel machte seinen Oheim, den Matthanja, an seiner Stelle zum König und änderte seinen Namen in Zedekia.

Die Parallele in II Chr 36 verkürzt die Darstellung dieser Ereignisse auf einen Vers (V.10):

An der Wende des Jahres sandte der König Nebukadnezar hin und ließ ihn (Jojachin) nach Babel holen samt den kostbarsten Tempelgeräten und machte seinen Bruder Zedekia zum König über Juda und Jerusalem.

$\overline{8 \quad \mathrm{~V} .13-14}$ sind sekundär; vgl. z.B. KITTEL, Die Bücher der Könige, $307 \mathrm{f}$. 
2. Auf der anderen Seite weiß Jer 52,28, daß Nebukadnezar in seinem 7. Jahr 3023 Judäer daportiert hat. Diese Notiz korrespondiert der Datierung der WISEMAN-Chronik. Zwar ist in Jer 52,28 der König Jojachin nicht genannt; und die babylonische Chronik ihrerseits spricht nur von Tribut, nicht aber von Deportierten. Trotzdem: An welches andere Ereignis wäre in Jer 52,28 zu denken als an dasselbe, das auch in II Reg 24,10-17 genannt ist: die erste Einnahme von Jerusalem ${ }^{9}$ ?

Angesichts der hier festzustellenden Diskrepanz fragen wir: Wie ist es zu erklären, daß diese Ereignisse einerseits in das 8., andererseits in das 7. Jahr der Regierungszeit des Nebukadnezar datiert werden? Zwei Versuche zur Lösung des Problems sind hier $\mathrm{zu}$ verhandeln.

1. Nimmt man an, daß im Gegensatz zu dem babylonischen Frühjahrskalender in Juda die Jahre im Herbst wechselten, ergibt sich die Möglichkeit, daß die Ereignisse im Zusammenhang mit der Einnahme Jerusalems nach dem judäischen Kalender in ein Jahr fallen, sich aber nach dem babylonischen Kalender auf zwei Jahre verteilen ${ }^{10}$. Wenn also das 11 . Jahr des Judäers Jojakim von Herbst 598 bis Herbst 597 gerechnet worden wäre, deckte es mit seiner ersten Hälfte (Herbst 598 bis Frühjahr 597) die zweite Hälfte des 7 . Jahres des Nebukadnezar, mit seiner zweiten Hälfte (Frühjahr bis Herbst 597) die erste Hälfte von dessen 8. Jahr ${ }^{11}$. In Nebukadnezars Jahr 7 gehört dann die Deportation yon 3023 Judäern nach Jer 52,28; die Masse der Exilierten - nach II Reg 2410000 (V.14) oder 7000 (V.16) mit dem König Jojachin an der Spitze - wurde erst nach dem 1. Nisan

9 Vgl. dazu auch unten $25 \mathrm{f}$.

10 So nach anderen MALAMAT, A New Record; DERS., The Last Kings of Judah; DERS., The Twilight of Judah; DERS., The Last Years (vgl. besonders 349 Anm.7); so auch (offenbar unabhängig von MALAMAT) FREEDY-REDFORD, The Dates in Ezekiel, $466 \mathrm{f}$.

11 MALAMAT, A New Record, 253f.; The Last Kings of Judah, 146ff.; The Twilight of Judah, $133 f$. 
( = 1. des 1. Monats) 597/6, also in Nebukadnezars Jahr 8 verschleppt ${ }^{12}$. Und wenn in II Chr 36,10 die "Wende des Jahres" ( $t s ̌ w b t h s ̌ n h$ ) als Zeitpunkt der Exilierung des Jojachin genannt ist, dann ist - nach MALAMAT - hier das Ziviljahr gemeint, das - anders als das Königsjahr - auch in Juda im Frühjahr, mit dem 1. Nisan, beginnt ${ }^{13}$.

Unter den Bedenken, die sich gegen diese chronologische Konstruktion erheben, sind die gegen das Rechnen mit zweierlei "Jahren" und die Verteilung der unterschiedlichen Angaben über die Zahl der Exilierten ${ }^{14}$ auf zwei Jahre die geringsten. Widerlegt wird die These von MALAMAT durch die alttestamentlichen Angaben selbst. Für Joahas sind nur 3 Monate Regierungszeit angegeben (II Reg 23,31). Daraus resultiert zwingend, daß er hier einmal die Herbstjahrrechnung für die judäischen Könige vorausgesetzt - vor dem Herbst-Neujahr, also vor dem 1. VII. (Tischri) 609 abgesetzt worden wäre ${ }^{15}$. Für seinen Nachfolger Jojakim - bedeutet das, daß er im Herbst, am 1. Tischri 609, sein Regierungsjahr 1 begonnen hätte - unabhängig davon, ob er noch vor dem 1. Tischri von dem Pharao eingesetzt worden ist;

12 MALAMAT, The Twilight of Judah, 133f.; The Last Years, 211.

13 MALAMAT, The Last Kings of Judah, 145f.; The Twilight of Judah, 133 (vgl. auch die Tabelle $144 \mathrm{f}$., auf der allerdings die "Ziviljahre" in Juda nicht registriert sind).

14 Die präzise Zahl 3023 in Jer 52,28 - neben den Angaben über 832 Exilierte im 18. und $745 \mathrm{im} \mathrm{23.} \mathrm{Jahr} \mathrm{Nebukadnezars} \mathrm{in}$ V. $29 \mathrm{f}$. - ist wesentlich vertrauenswürdiger als die größeren runden Zahlen $10000 \mathrm{bzw}$. 7000 in II Reg 24,14.16, von denen mindestens die erste zudem in offensichtlich jüngerem Text steht. Vgl. dazu weiter unten $26 \mathrm{f}$. Es ist auch nicht möglich, zu der runden Zahl von 7000 einer zweiten Deportation (II Reg 24,16) die 3023 aus Jer 52,28 als "3000" einer ersten Deportation hinzuzuzählen, um die Zahl von 10000 Deportierten nach 24,14 zu erreichen; gegen MALAMAT, The Last Years, 211.

15 Es bedarf also nicht des Versuchs, diesen Sachvernalt über ein Nachrechnen von Marschzeiten des ägyptischen Heeres nachzuweisen; so (nach anderen) CLINES in einer auch in anderen Punkten außerordentlich materialreichen und subtilen Studie: Regnal Year Reckoning in the Last Years of the Kingdom of Judah, $29 \mathrm{ff}$. mit dem Appendix 34. Denn hier ist über Wahrscheinlichkeit nicht hinauszugelangen; CLINES, 32. 
dann wäre die Frist von diesem Tage bis zum Jahresschluß am Ende des 6. Monats (Elul) der "Anfang seiner Regierung" (der Terminus in Jer 26,1) - oder nicht: Würde er nach dem 1. Tischri zum König gemacht, dann wäre trotzdem auf jeden Fall das ganze Jahr Herbst 609 bis Herbst 608 sein Jahr $1^{16}$. Nun hat Jojakim nach II Reg 23,36 11 Jahre regiert; sein 11. Regierungsjahr wäre also das Jahr Herbst 599 bis Herbst 598; und in dieses Jahr müßte auch die Frist von 3 Monaten Regierung des Jojachin und damit die Übergabe der Stadt Jerusalem an Nebukadnezar fallen. Dem widerspricht aber die Chronik WISEMAN, die dieses Ereignis auf den 2. Adar von Nebukadnezars Jahr $7=16$. März 597 verlegt. M.a.W.: Bei Herbstjahrrechnung würde die Regierungszeit des Jojakim von 11 Jahren einschließlich der drei Monate des Jojachin das gesicherte Datum 16. März 597 und damit das Herbs. jahr 598/7 nicht erreichen: Ein Jahr würde fehlen. Dieses fehlende Jahr gewinnt MALAMAT dadurch, daß er - unter der Annahme daß Jojakim erst nach dem 1. Tischri 609, also am Anfang des Jahres Herbst $609 / 8$, seinen Thron bestiegen habe 17 - für diese Jahr Herbst 609/8 entweder ein "Akzessionsjahr", d.h. ein ganzes Jahr "Anfang der Regierung" für Jojakim"18 oder ein "Jahr 1 für Joahas 19 annimmt, so daß beide Male das Jahr Herbst 608/7 Jojakims Jahr 1 wird. In diesem Fall würden die Ereignisse vom 16. März 597 in sein 11. Jahr fallen.

Beide Annahmen sind aber gleichermaßen unmöglich. Für Joahas sind in II Reg 23,31 nur 3 Monate Regierungszeit angegeben. Ob der Wechsel der Königsjahre im Frühjahr oder im Herbst liegt: Seine Regierungszeit hat das nächste Neujahr nicht erreicht, ein "Jahr 1" für Joahas (das erst an diesem Neujahr beginnen würde) gibt es nicht ${ }^{20}$. Aber auch das ganze Jahr Herbst 609/8

$16 \mathrm{Vgl}$. dazu auch unten 22.

17 The Last Kings of Judah, 140f.; The Twilight of Judah, 127

18 So die Tabelle A New Record, 256; The Last Kings of Judah, 147 Anm. 21 unter (b).

19 So The Twilight of Judah, 127 Anm. 9 unter (a) und die Tabelle 144. Vgl. Tabelle I unten 72 .

20 Gegen MALAMAT, The Last Years, 349 Anm. 8. Vgl. die oben genannte zweite Voraussetzung. 
dem Jojakim als Akzessionsjahr anzurechnen, geht nicht an. Denn auch ein solches selbständiges "Akzessionsjahr" würde dem System der Nachdatierung widersprechen. Gegenüber der "Vordatierung", die das Jahr eines Königswechsels sowohl dem Vorgänger (als sein letztes) als auch dem Nachfolger (als sein erstes) ganz zurechnet und so beim Zusammenzählen der Regierungsjahre pro König ein Jahr zuviel erhält, hat die Nachdatierung den Vorteil, daß die Addierung der Königsjahre mehrerer Könige die absolute Summe - ohne das Plus - ergibt ${ }^{21}$. Dieser Vorteil würde aufgegeben, wenn man einem Herrscher, der - nach dem Tod seines Vorgängers am Ende eines Jahres - etwa am Neujahrstag des nächsten Jahres oder kurz danach den Thron besteigt, dieses neue Jahr als "Akzessionsjahr", also in der Zählung der Jahre als "Jahr O" zurechnen würde. Die Verbindung der alttestamentlichen mit den babylonischen Angaben lehrt, daß für die Regierungsjahre der letzten judäischen Könige ein Wechsel im Herbst zwingend ausgeschlossen ist ${ }^{22}$. Die Könige in Juda haben - in der hier in Frage stehenden Zeit von Josia bis Zedekia - ihre Regierungsjahre von Frühjahr zu Frühjahr gerechnet ${ }^{23}$. Auf dem von MALAMAT versuchten Wege sind also die unterschiedlichen Datierungen der ersten Einnahme von Jerusalem im Alten Testament

21 Wir, die wir mit der Jahreszählung "vor Christus" eine absolute Zeitrechnung haben, können die Königsjahre (bei Vorliegen entsprechender Synchronismen) in dieses System einordnen und dabei - sofern es bekannt ist - ein Plus (bei einem einzelnen König oder beì allen Herrschern einer Reihe) ausschalten. Wo wie im Alten Orient eine solche absolute Chronologie nicht gegeben ist, fehlt für die Menschen jener Zeit auch die Möglichkeit einer Kontrolle, ob je Herrscher ein Jahr zuviel gezählt ist oder nicht. Das System der Nachdatierung ist ein Mittel, "absolute" Jahressummen zu gewinnen.

22 Damit erledigen sich auch andere Versuche, für die ausgehende Königszeit in Juda für alle oder für einzelne Bereiche eine Herbstrechnung der Jahre (mit dem Jahreswechsel im Herbst) zu postulieren, so etwa von THIELE, The Mysterious Numbers, 157; FREEDY-REDFORD, The Dates in Ezekiel, 466f.; SACK, Amel-Marduk, $30 f$.

23 Vgl. dazu CLINES, Regnal Year Reckoning, 32f. und - unabhängig davon - KUTSCH, Das Jahr der Katastrophe, $528 \mathrm{ff}$. 
(und in der babylonischen Chronik) in das 7. bzw. 8. Jahr Nebukadnezars nicht zu harmonisieren.

2. Ein anderer Versuch, die unterschiedlichen Datierungen der ersten Einnahme Jerusalems in das 7 . und in das 8. Regierungsjahr Nebukadnezars auszugleichen, geht davon aus, daß wie in Babylonien so auch (mindestens) in der ausgehenden Königszeit in Juda die Regierungsjahre der Könige im Frühjahr, zum 1. Nisan, wechselten. In diesem Fall werden dann die einzelnen Vorgänge im Zusammenhang der Einnahme der Stadt nicht nur für die babylonische, sondern auch für die judäische Zeitrechnung auf zwei Jahre verteilt ${ }^{24}$, genauer: auf die Tage zwischen dem 2. Adar des Jahres 598/7 ( = 16. März 597) und dem letzten Tag dieses Monats $(=12$. April 597) einerseits, die Tage ab dem 1. Nisan 597/6 (= 13. April 597) andererseits ${ }^{25}$. Nach der babylonischen Königschronologie gehört die Frist vor dem 1. Nisan $597 \mathrm{zu}$ dem 7. Jahr des Nebukadnezar, die Zeit ab dem 1. Nisan zu seinem 8. Regierungsjahr. Die Einnahme der Stadt durch Nebukadnezar bzw. ihre Übergabe durch Jojachin fand am 2. Adar, also gegen Ende des Jahres 598/7 statt. Der Doppelung der Aussage in II Reg 24,12a und b - "Jojachin, der König von Juda, ging hinaus (aus Jerusalem) zu dem König von Babel, er und seine Mutter, seine Hofbeamten, Obersten und Kämmerer" sowie "und der König von Babel nahm ihn gefangen im 8. Jahr seiner Regierung" - entnimmt VOGT, daß Nebukadnezar den Jojachin zunächst, d.h. in den letzten Tagen seines 7. Regierungsjahres, "in seiner Gewalt" gehabt habe (so V.12a); "genommen" (Verbum laqăh) d.h. "festgenommen" habe er ihn (so V.12b) aber erst in seinem

24 So VoGT, Jahr der Eroberung Jerusalems, 226ff.; vgl. schon: DERS., die neubabylonische Chronik, $94 \mathrm{f}$. - Im Gegensatz zu MALAMAT setzt in demselben Band, The World History of the Jewish People. IV/1, TADMOR, The Chronology of the First Temple Period, für die letzten judäischen Könige, die Frühjahrsrechnung der Regierungsjahre - mit dem 1. Nisan als Neujahrstag - voraus.

25 Für die Gleichungen antiker Daten mit unserer Zeitrechnung vgl. PARKER-DUBBERSTEIN, Babylonian Chronology, 27. 
8. Jahr, also nach dem 1. Nisan $597^{26}$. Das ergibt für ihn die Kombination dieser stelle mit II Chr 36,10, wonach Nebukadne-

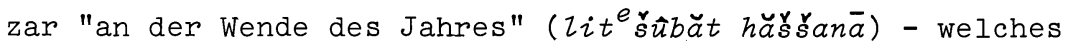
Regierungsjahr dies gewesen sei, wird anders als in II Reg 24,12 nicht gesagt - den Jojachin sowie kostbare Tempelgeräte nach Babel bringen ließ. Auch die Einsetzung des Zedekia ist nach diesem Text - möglicherweise erst "Wochen nach Neujahr"27 erfolgt.

Hintergrund für diese Argumentation ist die Frage nach der Datierung der zweiten Eroberung Jerusalems am Ende der Regierungszeit des Zedekia. Nach II Reg 25,3f. (8) und Jer 52,6f. (12) erfolgt sie am 9. IV. (der 4. Monat ist in II Reg nach Jer zu ergänzen) im 19. Jahr Nebukadnezars $(=586 / 5)$, also nach VOGT im Sommer 586. Dieses Jahr $586 / 5$ ist zugleich das 11. und letzte Jahr des Zedekia (vgl. II Reg 25,2; Jer 52,5). Rechnet man von diesem zurück auf das erste Jahr des Zedekia, kommt man auf das Jahr 596/5. Das Todesjahr des zweiten Vorgängers, Jojakim, in das (auch nach VOGT) wenigstens die Absetzung des Jojachin fiel, ist - daran läßt die WISEMANN-Chronik keinen Zweifel - das Jahr 598/7. So klafft zwischen diesem Jahr und dem Jahr 1 des Zedekia eine Lücke von einem Jahr. Diese Lücke füllt VOGT auf durch die Annahme eines "Akzessionsjahres" für Zedekia, das in dieses Jahr 597/6 zu rechnen $\operatorname{sei}^{28}$

Nun ist - um hier einzusetzen - II Chr 36,10 nicht ein Text, dem unbesehen historische Zuverlässigkeit zuzuschreiben wäre.

26 VOGT, Jahr der Eroberung, 229; Vgl. schon DERS., Die neubabylonische Chronik, 94.

27 VOGT, Jahr der Eroberung, 227.

28 Jahr der Eroberung, 228. Ebenso TADMOR, The Chronology of the First Temple Period, 56. Mit VOGT geht auch LANG, Ezechiel, $32 \mathrm{ff.}$, bei der Umrechnung der Daten des Ezechielbuches in unsere Zeitrechnung aus von der "synchronistischen Formel" "Jahr 1 der Ära Jojachin = Jahr 0 der Ära Zidkija = Jahr 8 der Ära Nebukadrezzar" Ezechiel, 32. S. die Tabelle II unten 73 . 
Wenn wir über die Ereignisse um den 2. Adar des 7. Jahres des Nebukadnezar - so die babylonische Chronik - keine andere Nachricht hätten als II Chr 36,10, wüßten wir nichts davon, daß Nebukadnezar die Stadt Jerusalem belagert und angegriffen, daß der judäische König Jojachin die Stadt - vier Wochen vor Ende des Jahres 598/7 - übergeben hat und daß in diesem Zusammenhang eine (erste) Deportation von - nach Jer 52,28: 3023 - Judäern nach Babel erfolgt ist ${ }^{29}$. Die einzige Zeitangabe in diesem Text, Zit éŝubăt hăšśanā "an der Wende des Jahres", versteht VOGT mit zahlreichen Auslegern als "Jahreswende" in unserem Sinn, d.h. als den Übergang von einem Jahr zum nächsten. Daß die hebräische Wendung dies tatsächlich meint, ist mindestens unsicher, eher aber unwahrscheinlich. In II Sam 11,1 ist damit die Zeit, "in der die Könige (zum Krieg) ausziehen", und das heißt der Frühommer 30 bezeichnet. Da zur Zeit Davids die Jahre sicher nicht im Frühjahr, sondern im Herbst wechselten, bezeichnet der Ausdruck "an der Wende des Jahres" hier nicht den Jahreswechsel, sondern die Mitte des Jahres, also jene Zeit, in der das Jahr sich seinem Ende zu"wendet". Wenn auch nicht $\mathrm{zu}$ beweisen, aber doch wahrscheinlich ist, daß die Datierung "an der Wende des Jahres" in II Chr 36,10 - nun bei Frühjahrsrechnung - die "Wende" im Herbst meint. Die Zeitangabe würde durchaus dazu passen, daß Nebukadnezar im 9. Monat seines 7. Jahres nach Jerusalem aufgebrochen ist ${ }^{31}$. Hat der Chronist "an der Wende des Jahres" in dieser Weise verstanden, dann setzt - da er von "Neujahr" o.ä. (im Frühjahr) nichts sagt auch er voraus, daß alze Ereignisse: Übergabe der stadt, Gefangennahme Jojachins (samt seiner Familie und seines Hofes), Deportation Jojachins und einer großen Zahl Judäer, die Verschleppung der Tempelgeräte sowie die Einsetzung des Zedekia

29 Zur Tendenz dieser Verkürzung vgl. GALLING, Die Bücher der Chronik, $183 f$.

$30 \mathrm{Vgl}$. auch I Reg 20,22.26. - Für Mesopotamien vgl. etwa ANET $277 \mathrm{a} .278 \mathrm{~b}$ (Salmanassar III.).303b.304.305a (Nabopolassar). $306 a$ (Kyros).

31 S. Anm. 35 . - Die Angabe "an der Wende des Jahres" in I Chr 20,1 ist aus II Sam 11,1 übernommen und durch den Hinweis auf den Zeitpurit des Feldzugbeginns auf das Frühjahr fixiert. 
noch in das Jahr, in dem die Aktion gegen Juda eingeleitet wurde, d.h. in das 7. Jahr des Nebukadnezar gefallen sind.

Mag an diesem Punkt auch nicht völlige Sicherheit zu erreichen sein, so schließen doch zwei weitere Argumente die hier diskutierte Konstruktion aus. Aus dem System der Nachdatierung ergibt sich viererlei:

1. Ein selbständiges "Akzessionsjahr", also ein Jahr, das weder dem Vorgänger als letztes noch dem neuen König als erstes Jahr zugerechnet wird, gibt es nicht; es wäre ein Jahr 0 , durch das dem neuen König ein Jahr zuviel zugeschrieben würde ${ }^{32}$. Das Jahr 597/6 war also nicht "Antrittsjahr" Zedekias, sondern auf jeden Fall sein Jahr 1. Das gilt, ob Zedekia vor dem Jahreswechsel eingesetzt wurde oder danach. Im zweiten Fall würde das vorangegangene Jahr (598/7) systemgerecht ganz dem in diesem Jahr, seinem 11. Regierungsjahr, verstorbenen Jojakim zugerechnet; das neue Jahr war, auch wenn Zedekia erst nach dem Jahresbeginn eingesetzt worden wäre, sein "Jahr 1" - einer Zeit "im Anfang seiner Regierung" bedurfte es hier nicht.

2. Das Alte Testament läßt keinen Zweifel daran, daß Zedekia von Nebukadnezar vor dem Ende des Jahres $598 / 7$ als König eingesetzt worden ist. In Jer 49,34 ist der Spruch gegen Elam in den "Anfang der Regierung des Zedekia" datiert 33 . Hier ist also vorausgesetzt, daß Zedekia noch in den Tagen des Adar des 7. Jahres Nebukadnezars, des Jahres 598/7, auf den Thron gesetzt worden ist ${ }^{34}$. Die ausdrückliche Bestätigung dafür liefert die babylonische Chronik (B.M. 21946 Rev. 13) 35.

3. Da für Jojachin nur drei Monate Regierungszeit angegeben sind (II Reg 24,8), ist er bei der Einnahme von Jerusalem nicht nur "in die Gewalt" des Nebukadnezar gekommen, sondern wurde

32 S. dazu oben 18 und die Tabelle II unten 73.

$33 \mathrm{Zu}$ dieser Zeitangabe in Jer $(27,1 ;) 28,1 \mathrm{vgl}$. die Kommentare.

34 RUDOLPH, Jeremia, 295.

35 WISEMAN, Chronicles, $72 f$. 
alsbald - jedenfalls noch vor dem Ende des letzten Monats (Adar) des Jahres 598/7 - von diesem ab- und gefangen gesetzt.

4. Daß Nebukadnezar sofort nach der Einnahme von Jerusalem die Deportierung der Oberschicht der stadt begonnen hat, legt auch Jer 1,3 nahe. Danach erfolgte die Wegführung nach Babylonien nach der (zweiten) Eroberung der Stadt am 7. V. Jahr 11 des Zedekia noch im 5., d.h. in demselben Monat.

Das Alte Testament und die babylonische Chronik stimmen also in der Angabe überein, daß Nebukadnezar noch vor dem Ende des Jahres 598/7 Jojachin durch Zedekia ersetzt hat. Der entscheidende Unterschied zwischen beiden Quellen liegt darin, daß die WISEMAN-Chronik den Thronwechsel in das 7. Jahr des Nebukadnezar datiert (vgl. auch Jer 52,28), II Reg 24,12 aber in dessen 8. Jahr. Wie kommt es nun zu dieser Diskrepanz in der Zählung der Jahre des Nebukadnezar? Die Antwort: Im Alten Testament liegen zwei verschiedene Weisen vor, die Regierungsjahre des Nebukadnezar zu zählen, zwei Systeme. Dies ist hier - wiederum in Kürze - aufzuzeigen ${ }^{36}$.

Das erste System: Jerusalem wurde eingenommen, Jojachin wurde deportiert im 7. Jahr Nebukadnezars - dem entspricht in Jer 52,28 die Deportierung von 3023 Judäern in diesem Jahr. Es ist das Jahr 598/7. Für die zweite Eroberung Jerusalems mit der Zerstörung des Tempels fehlt (noch) die Datierung in einer babylonischen Quelle. Jer 52,29 führt eine Deportierung von 832 Judäern im 18. Jahr des Nebukadnezar auf. Diese liegt $11 \mathrm{Jahre}$ nach der ersten, also im Jahr 587/6. Das ist in der Tat das 18. Jahr des Babyloniers; und es ist, da Zedekias erstes Jahr das Jahr 597/637 und Zedekia nach II Reg 24,18 11 Jahre König war, das 11. und letzte Jahr dieses Herrschers. Da er seinen Thron im Zusammenhang der Eroberung der Stadt verloren hat, ist dieses Jahr 587/6 - das 18. Jahr Nebukadne-

36 S. dazu Tabelle III unten 74 und $\mathrm{vgl}$. bereits KUTSCH, Das Jahr der Katastrophe, $534 \mathrm{ff}$.

37 S. oben 22. 
zars und das Jahr der zweiten Deportierung - auch das Jahr der zweiten Eroberung der Stadt ${ }^{38}$.

Das zweite System: Parallel dazu gehen die Angaben von II Reg 24,12 und II Reg 25,3f.8 = Jer 52,6f.12, die die beiden Eroberungen Jerusalems in das 8 . und das 19. Jahr des Nebukadnezar verlegen. Der Abstand ist derselbe: 11 Jahre - entsprechend auch den 11 Jahren der Regierung des Zedekia. Nur: Beide Angaben über das jeweilige Regierungsjahr des Nebukadnezar sind um eine Ziffer $\mathrm{zu}$ hoch.

In dieses zweite system gehört auch das Jahwewort, das zur Zeit der Belagerung Jerusalems - sie begann am 10. X. des 9. Jahres des Zedekia (II Reg 25,1) - nach Jer 32,1ff. an Jeremia erging. Es ist in das 10. Jahr Zedekias datiert, das hier mit dem 18. Jahr Nebukadnezars gleichgesetzt ist.

Dieses zweite System läßt sich im Alten Testament auch noch weiter zurückverfolgen. In Jer 25,1 wird ein Wort an den Propheten Jeremia in das 4. Jahr Jojakims datiert, das ist das Jahr 605/4. Dieses 4. Jahr Jojakims sei identisch mit dem 1. Jahr des Nebukadnezar. Auch diese Angabe ist um ein Jahr zu hoch: Nebukadnezar hat erst in diesem Jahr, am 1. Elul, den Thron bestiegen, wie der babylonischen Chronik zu entnehmen ist (B.M. 21946 Obv. 11); der Rest dieses Jahres ist noch der "Anfang seiner Regierung", sein Jahr 1 ist erst das Jahr 604/603. - Derselbe Fehler liegt in Jer 46,2 vor, wo Nebukadnezar als Sieger über die Ägypter bei Karkemisch als "König" bezeichnet wird; er war aber ausweislich der babylonischen Chronik (B.M. 21946 Obv. 1-7) zu diesem Zeitpunkt noch Kronprinz. So ist offenbar auch hier das Regierungsjahr des Babyloniers um ein Jahr hinaufgerückt.

Dem ersten System entsprechen die einschlägigen Datierungen bei Josephus: Er setzt (richtig) Jojakims 4. Jahr mit dem "Anfang

38 Cf. KUTSCH, Das Jahr der Katastrophe, 520ff., besonders die Tabelle 544. So z.B. auch FINEGAN, Handbook, $206 \mathrm{f}$. 
der Regierung" des Nebukadnezar gleich (ant. X,84), sein 8. mit dem 4. des Nebukadnezar (ant. X,87) und schließlich das 18. (nicht das 19.) des Nebukadnezar mit dem 11. des Zedekia (ant. $\mathrm{X}, 146$; c.Ap. I,154).

Im Alten Testament sind also zwei systeme mit Angaben über Regierungsjahre des Nebukadnezar nachzuweisen, die zwar einander parallel laufen, aber um ein Jahr differieren. In beiden Systemen beginnen die Königsjahre in Juda wie in Babylonien im Frühjahr. Von den Angaben dieser Systeme stimmen die beiden aus System I mit den Daten der babylonischen Chronik überein. Demgegenüber setzen alle Angaben von System II - alle 39 , nicht nur die beiden dem System I parallelen ! - das jeweilige Regierungsjahr des Nebukadnezar um ein Jahr höher an. Nur eines von beiden kann richtig sein. Die beiden Systeme sind also von unterschiedlichem Wert. Dieser Sachverhalt ist durch einen weiteren Argumentationsgang noch deutlicher herauszustellen.

1. Die Angaben des ersten Systems sind auf einen. Text beschränkt, auf Jer 52,28-30. Das Kapitel 52 des Jeremiabuches gibt von V.4 an weithin die Darstellung von II Reg 25 wieder mit zwei Ausnahmen: Die Verse II Reg 25,22-26, die "selbst ein Auszug aus Jer 39-41" sind 40 , wurden weggelassen; die Verse Jer 52,28-30 dagegen wurden in den aus II Reg übernommenen Text eingeschaltet. Sie bieten im Anschluß an die zusammenfassende Notiz: " So ging Juda (nach der zweiten Eroberung Jerusalems) aus seinem Land weg in die Gefangenschaft" (V.27b = II Reg 25,21b) eine Aufstellung über die in die Verbannung nach Babylonien geführten Judäer und Jerusalemer: im 7. Jahr des Nebukadnezar 3023 Judäer (V.28), im 18. Jahr 832 Seelen aus Jerusalem (V.29), im 23. Jahr von dem Obersten der Leibwache, Nebusaradan, der schon bei der Eroberung der stadt eine hervorragende Rolle gespielt hat (II Reg 25,8ff. = Jer 52,12ff.),

39 Es sind fünf: Jer 25,1; 46,2; II Reg 24,12; Jer 32,1;

II $\operatorname{Reg} 25,8=\operatorname{Jer} 52,12$.

40 RUDOLPH, Jeremia, 319. 
deportiert 745 Seelen (V.30a), insgesamt 4600 Seelen (V.30b). Selbst wenn die eine oder andere Zahl "frisiert" worden wäre, damit der glatte Hunderter "600" herauskäme" 41 , sind die Angaben über die Deportierten im ganzen doch vertrauenswürdig.

Andererseits hat man das Datum der ersten hier genannten Deportierungen vom "7." in das "17." Jahr des Nebukadnezar ändern wollen ${ }^{42}$. Für diese Emendation wurde der Sachverhalt angeführt, daß für die drei Deportationen unterschiedliche Personengruppen angegeben werden - Judäer, Leute aus Jerusalem und wieder Judäer ${ }^{43}$. Jedoch: $j^{e} h \hat{u} d \hat{\imath} m$ "Judäer" schließt die Bewohner von Jerusalem - sofern die Stadt besteht - immer ein; vgl. z.B. Jer 32,12; 34,9; Neh 1,2; 3,33. So sind in Jer 52,28 in $j^{e}$ hûd die Bewohner von Jerusalem einbezogen, in V.30 wohl nicht, sofern hier die Verwüstung der stadt vorausgesetzt ist. Der Angabe von V.29, daß bei der zweiten Eroberung der Stadt Leute "aus Jerusalem" weggeführt wurden, entspricht, daß nach II Reg 25,11 "der Rest des Volkes, was in der Stadt übrig geblieben war," von der Babyloniern deportiert wurde, während nach V.12 "von den Geringen des Landes Weingärtner und Ackerbauer" zurückgelassen wurden. So liegt für diese Textänderung kein Anlaß vor.

Die in Jer 52,28-30 angegebenen Zahlen beruhen wohl auf konkreten Unterlagen. Zum Vergleich wird man die in Esr 2 und Neh 7 mitgeteilte "Heimkehrerliste" 44 heranziehen dürfen. Ähnlich wie diese Liste bzw. ihre Vorlage aus konkretem Anlaß in Palästina zusammengestellt wurde 45 , hat man in Babylonien die dort

$41 \mathrm{Vgl}$. RUDOLPH, Jeremia, 324.

42 So nach dem Vorgang zahlreicher anderer RUDOLPH, Jeremia, 324; auch in BHS ist die Änderung wenigstens erwogen.

43 So RUDOLPH, Jeremia, 324.

44 Vgl. dazu GALLING, Die Liste der aus dem Exil Heimgekehrten.

45 Vgl. dazu GALLING, Die Liste der aus dem Exil Heimgekehrten, $107 f$. 
angekommenen bzw. angesiedelten Deportierten in Listen erfaßt ${ }^{46}$, sei es im Anschluß an die jeweilige Deportation, sei es auf einmal nach der dritten Verschleppung 47 .

Es ist also davon auszugehen, daß die Datierungen wie die Deportiertenzahlen in Jer 52,28-30 zuverlässig und hinsichtlich der ersten Deportation den in II Reg 24,14 bzw. 16 genannten runden und offenbar überhöhten Zahlen von $10000(t \mathrm{x}) \mathrm{bzw}$. von $7000(+1000)$ Verschleppten vorzuziehen sind 48 .

2. Im zweiten System haben wir zwei verschiedene Datierungsarten.

a) In drei der fünf Angaben dieses Systems, nämlich in II Reg 25,8 (= Jer 52,12); Jer 25,1 und 32,1, ist die zweite Zeitan-

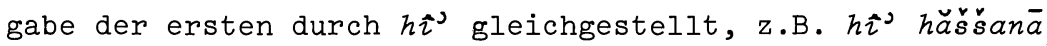
hari’šont̂t $Z_{i n}{ }^{e} b \hat{u k a d r a ̈ ’ s s a ̆ r ~ " d a s ~ i s t ~ d a s ~ e r s t e ~ J a h r ~ d e s ~ N e b u-~}$ kadnezar" (Jer 25,1). Dieses Schema findet sich auch sonst im Alten Testament: in II Reg 18,9.10; Ez 1,2; Esr 7,7f. und (aram.) 6,15. In Ez 1,2 ist mit Hilfe der Wiederaufnahme der

46 Die auf dem Gefangenentreck von Palästina nach Babylonien Umgekommenen wird man sicher nicht auch noch aufgenommen haben.

47 Dafür, daß man in Mesopotamien seit alters unter verschiedenen Gesichtspunkten Listen von Personen zusammengestellt hat, gibt es reichliche Belege; z.B.: EDZARD, Sumerische Rechtsurkunden des III. Jahrtausends, Nr. 105 (Zeugenliste [?], Zeit 2400-2370); KOHLER-UNGNAD, Hammurabi's Gesetz. Band $\mathrm{V}, \mathrm{Nr}$. 1318-1398, darunter besonders eine Liste von Frauen in Nr. 1364 (VS IX,172) sowie eine große Liste in Nr. 1398 (CT VI, 15-18); Zeit Hammurabi und später; KOSCHAKER-UNGNAD, ebenda Band VI, Nr. 1958.1959.1963.1967.1969. 1970; undatiert; WEISBERG, Guild Structure and Political Allegiance in Early Achaemenid Mesopotamia, $5 \mathrm{ff}$. (Liste von Personen mit demselben Beruf; Zeit des Kyros) (freundlicher Hinweis von Prof. Dr. Hermann HUNGER, Wien); SAN NICOLOUNGNAD, Neubabylonische Rechts- und Verwaltungsurkunden I, $\mathrm{Nr} .666$ (VS VI,70,7, Zeit des Nabonid): Ein Mann läßt sich als "Bogenmann" in eine Stammrolle einschreiben. - Zu Stammrollen über Soldaten bzw. Sklaven in Hammurabis bzw. neubabylonischer Zeit vgl. MEISSNER, Babylonien und Assyrien $\mathrm{I}, 84 \mathrm{bzw} .382$.

48 Über die dritte Deportation (im 23. Jahr des Nebukadnezar = $582 / 1$ ) fehlt uns sonst (bis jetzt) jegliche Nachricht. 
Tagesangabe "am 5. des Monats" aus V.1 das schwer verständliche Datum "im 30. Jahr" aus V.149 durch die Angabe "das ist ( $h \hat{\imath}^{2}$ ) das 5. Jahr der Wegführung des Königs Jojachin" erklärt. In Esr 7,8 wird mit "hरे" lediglich die Angabe des 7. Jahres des Artaxerxes aus V.7 wiederholt und in 6,15 das bisher nicht genannte 6 . Jahr der Regierung des Königs Darius mit $d \hat{\imath} h \hat{\imath}^{2}$ nachgetragen ${ }^{50}$. Dafür, daß solche Jahresgleichungen falsch sein können, bietet II Reg 18,9.10 ein anschauliches Beispiel ${ }^{51}$. In einer im Grundbestand aus judäischer Quelle stammenden Notiz werden dem 4. und dem 6. Jahr des judäischen Königs Hiskia, in denen die Belagerung der Hauptstadt des Nordreiches, Samaria, durch den Assyrer Salmanassar V. begonnen bzw. zu Ende geführt worden sei, - sekundär - das 7. bzw. 9. Jahr des israelitischen Königs Hosea gleichgesetzt. Hier ist das Ende der nach II Reg 17,1 neunjährigen Regierungszeit des Hosea mit der Eroberung der Hauptstadt zusammengestellt worden - zu Unrecht, wie sich daraus ergibt, daß nach 17,4f. Hosea bereits vor Beginn der Belagerung von dem Assyrer gefangen genommen wurde und daß die 9 Jahre Regierungszeit des Hosea von seiner Einsetzung durch Tiglatpilesar III. in dessen 14. Regierungsjahr, im Jahr $732 / 1^{52}$, nur bis $724 / 3$, nicht aber bis $722 / 1$ reicht.

Nehmen wir nun die drei hierher gehörenden stellen des zweiten Systems, II Reg 25,8 ( = Jer 52,12); Jer 25,1 und 32,1 in den Blick. In II Reg 25,8 (=Jer 52,12) fällt auf, daß die Gleichsetzung "dies ist $\left(h \hat{\imath}^{2}\right)$ das 19. Jahr des Königs Nebukadnezar, des Königs von Babel," nicht auf eine Jahresangabe Bezug nimmt, sondern nur auf die Datierung "im 5. Monat am 7. (II Reg) / 10.

49 S. dazu unten $45 \mathrm{ff}$.

50 Entsprechend wird in Esr 10,9 die ganze Datierung des 20. IX. eingeführt. - Auch Erklärungen älterer Monatsbezeichnungen durch neuere können durch die Formel "hî" hăhodäs..." erfolgen, so in I Reg 6,1.38; 8,2; Sach 1,7; in Sach 7,1 geschieht dies durch einfachen Zusatz "im (Monat) Kislev".

51 Auf das vielschichtige Problem der zahlreichen Synchronismen zwischen Herrschern des Nord- und des Südreiches nach dem - andersgearteten - Schema: "Im 18. Jahr des Königs Jerobeam ben Nebat (von Israel) wurde Abia König über Juda" (I Reg 15,1) ist in diesem Zusammenhang nicht einzugehen.

52 Vgl. GALLING, Textbuch, Nr. 26 und 27, sowie II Reg 15,30. 
(Jer) des Monats". Hinzu kommt, daß das Jahr, das hier in Frage steht, bereits zuvor genannt und nach der Regierung des judäischen Königs, Zedekia, bestimmt war (II Reg 25,2 = Jer 52,5): "Die stadt geriet in Belagerung bis zum 11. Jahr des Königs Zedekia," und daß zudem anschließend ein Ereignis aus dem 4. Monat dieses Jahres 53 berichtet ist (II Reg 25,3ff. = Jer $52,6 \mathrm{ff}$.$) . In keinen Annalen wird ein so wichtiger Synchronismus$ erst an so später Stelle des Berichtes und in so unlogischer Weise gebraucht. Das bedeutet: Die Vorlage zu der Darstellung der Ereignisse in II Reg 25 hat diesen Synchronismus von V.8 nicht enthalten! Er ist erst von dem - deuteronomistischen Verfasser dieses Abschnittes hierher gesetzt. Nur das letzte, das entscheidende Ereignis in diesem Abschnitt der Geschichte, die Eroberung, Plünderung und Zerstörung Jerusalems, wird "synchronisiert".

Noch weniger als II Reg 25,8 = Jer 52,12 gehen die zeitlichen Ansätze in Jer 25,1 und 32,1 auf eine zuverlässige Quelle zurück. Auch hier ist ein späterer ${ }^{54}$, genauer: deuteronomistischer ${ }^{55}$ oder noch späterer Verfasser 56 am Werk, dem die Höheransetzung der Regierungsjahre des Nebukadnezar im Vergleich zu den judäischen Königen - Jer 25,1: Nebukadnezar 1 = Jojakim 4; 32,1: Nebukadnezar 18 = Zedekia 10 - bereits vorgegeben war. b) In II Reg 24,12 und in Jer 46,2 wird jeweils ein bestimmtes Ereignis in ein Regierungsjahr des Nebukadnezar angesetzt durch den präpositionalen Ausdruck "im Jahr x ...". In II Reg 24,12 folgt die Zeitangabe "im 8. Jahr des Nebukadnezar" erst nach der Notiz über die Gefangennahme des judäischen Königs

53 Die Monatsangabe findet sich nur in Jer 52,6, stand aber ursprünglich auch in II $\operatorname{Reg} 25,3$.

54 DUHM, Jeremia, 200. 260; ROTHSTEIN, Jeremia, 796.817; BRIGHT, Jeremiah, 160 ( zu 25,1); RUDOLPH, Jeremia, $207 f$. ( zu 32,1$)$.

55 LESLIE, Jeremiah, 155.239; RUDOLPH, Jeremia, XVII. 159 (zu 25,1).

56 HYATT, Jeremiah, 999 ( $z$ 25,1: mit LXX, in der in V.1-7 u.a. V. 1b fehlt); THIEL, Jeremia 1-25, 268 ( zu 25,1); DERS., Jeremia 26-45, 30 ( zu 32,1). 
Jojachin - und das, nachdem zuvor in V.10 für den Beginn der Ereignisse, den Anmarsch des Babyloniers, lediglich die allgemeine Zeitangabe "in jener Zeit" (nämlich in der Zeit des in V.8f. genannten Jojachin) vermerkt war. Hier wie in II Reg 25,8 ist die Datierung in das 8. Jahr Nebukadnezars nicht Annalen entnommen, sondern von dem (deuteronomistischen) Verfasser auf Grund eines ihm vorgegebenen Schemas nachgetragen.

Nicht anders ist schließlich auch die Entstehung der sekundären Erweiterung der ursprünglichen Überschrift "an Ägypten" in Jer 46,2 zu erklären, die die Schlacht bei Karkemisch zwar richtig in das 4. Jahr des Jojakim ansetzt, den Nebukadnezar aber, der nach der babylonischen Chronik noch als Kronprinz den Sieg über die Ägypter errungen hat, fälschlicherweise bereits als König bezeichnet 57 .

Aus diesen Feststellungen ergeben sich zwei wichtige Folgerungen:

1. Da System I im Alten Testament besser bezeugt ist und zudem den babylonischen Daten entspricht, gibt dieses den historischen Sachverhalt wieder. Jerusalem ist also im 7 . und im 18 . Jahr des Nebukadnezar erobert worden (nicht im 8. und 19. Jahr, so System II). Das Jahr der ersten Einnahme der Stadt, 598/7, steht durch die Angabe der babylonischen Chronik fest; für die zweite Eroberung, die zur Zerstörung Jerusalems und des Tempels gefuhrt hat, ergibt sich zwingend das Jahr $587 / 6$ als Nebukadnezars 18. Regierungsjahr 58 .

2. Da es sich um zwei in sich geschlossene, einander parallele Datierungssysteme handelt, ist es nicht möglich, Daten aus den beiden systemen miteinander in einer chronologischen Reihe in Verbindung zu setzen, konkret: das Jahr 8 des Nebukadnezar

$57 \mathrm{Vgl}$. die letzte spalte in Tabelle III unten 74.

58 Die System I entsprechenden Angaben des Josephus sind also ebenfalls richtig. 
(nach II Reg 24,12 ) aus dem zweiten System auf Nebukadnezars Jahr 7 des ersten Systems (nach Jer 52,28) folgen zu lassen. Beide Angaben meinen ein und dasselbe Jahr: 598/7 59 .

Wie aber - so fragen wir zum Abschluß dieses ersten Teiles ist es zu dieser Höheransetzung der Regierungsjahre des Nebukadnezar in dem hier ermittelten zweiten System gekommen? Der Anlaß ist wohl im Zusammenhang der Ereignisse des Sommers des Jahres 605/4 zu suchen, genauer darin, daß den Feldzug gegen die Ägypter in diesem Sommer ausweislich der babylonischen Chronik ${ }^{60}$ nicht mehr der wohl schon kranke König Nabopolassar geführt hat, sondern - noch als Kronprinz! - sein Sohn Nebukadnezar. Erst nach der Schlacht erreicht diesen die Nachricht, daß sein Vater am 8. Abu ( $=15$. Aug. 605 ${ }^{61}$ ) gestorben ist. $\mathrm{Ne}-$ bukadnezar eilt nach Babylon und besteigt am 1. Elul ( $=7$. Sept. $605^{62}$ ) den königlichen Thron ${ }^{63}$. Damit beginnt für ihn der "Anfang seiner Regierung", und er begibt sich sofort wieder nach Westen, um Syrien - das "Land Hatti" - ganz in seine Gewalt zu bringen und den "schweren Tribut des Landes" zu empfangen ${ }^{64}$. Erst am 1. Nisan des nächsten Jahres $(=2$. April $604^{65}$ ) beginnt sein Jahr 1. Daß im Sommer 605 nicht Nabopolassar, sondern Nebukadnezar das babylonische Heer angeführt hat, konnte die - falsche - Annahme hervorrufen, er sei zu dieser Zeit bereits König gewesen. Daß dieser Irrtum in ganz Syrien und Palästina verbreitet gewesen ist ${ }^{66}$, wird man wohl bezweifeln. Offensichtlich hat jedenfalls unter den Judäern - auch in der Verbannung - zunächst wohl ein kleiner Kreis in dem

$59 \mathrm{Vgl}$. Tabelle III unten 74.

60 B.M. 21946 Obv. $1 \mathrm{ff}$.

61 PARKER-DUBBERSTEIN, Babylonian Chronology, 27.

62 PARKER-DUBBERSTEIN, Babylonian Chronology, 27.

63 B.M. 21946 Obv. $10 f$.

64 B.M. 21946 Obv. $12 f$.

65 PARKER-DUBBERSTEIN, Babylonian Chronology, 27.

66 So ALBRIGHT, Chronicles, 32. 
Sieger von Karkemisch Nebukadnezar den König gesehen und damit das Jahr der Schlacht bereits als sein Jahr 1 verstanden 67 und so die Verwirrung hervorgerufen, die bis heute die Gelehrten beschäftigt.

$67 \mathrm{Vgl}$. KUTSCH, Das Jahr der Katastrophe, $540 \mathrm{ff}$. 
II. Die Daten im Buch Ezechiel.

Für unsere Untersuchung über die Datierungen im Ezechielbuch halten wir folgende wichtige Ergebnisse fest:

1. In der ausgehenden Königszeit in Juda begannen bürgerliches und Königsjahr im Frühjahr.

2. Der judäische König Jojachin ist noch im Monat Adar, dem letzten Monat des Jahres 598/7, von dem babylonischen König Nebukadnezar abgesetzt und von Jerusalem nach Babel deportiert worden.

3. Die zweite Eroberung von Jerusalem und die Zerstörung von Stadt und Tempel durch die Babylonier erfolgten im Sommer 587 v. Chr.

Wenden wir uns nun den Datierungen zu, die das Ezechielbuch enthält. Es empfiehlt sich, bei den Angaben von Ez 40,1 einzusetzen, da hier das Hauptproblem, die Zählung der Jahre der Verbannung des Königs Jojachin, am besten zu demonstrieren ist

1. $\operatorname{Ez} 40,1$

Ez 40,1 datiert die Vision des Propheten Ezechiel über das zukünftige Jerusalemer Heiligtum folgendermaßen:

Im 25. Jahr unserer Verbannung, am "Haupt des Jahres ( $b^{e}$ ro s hassanā)", am 10. des Monats, im 14. Jahr, nachdem die stadt (Jerusalem) geschlagen worden war.

In diesem Datum bereitet - für uns ein Nebenproblem - die Angabe $b^{e}$ ro $s$ hassanā der Auslegung Schwierigkeiten; auf diese ist hier vorweg kurz einzugehen.

Zahlreiche Ausleger verstehen die Wendung so, wie sie später i der Mischna usw. ${ }^{6}$ gebraucht wird: als Bezeichnung des Neujahr tages, des Tages, an dem ein neues Jahr beginnt, nämlich

68 Mischna, Talmud und Tosephta haben eigene Traktate unter dieser Bezeichnung. 
des 1. VII. (= Tischri, im Herbst) ${ }^{69}$. Bereits die Septuaginta sah demgegenüber in der Angabe eine Bezeichnung für den ersten

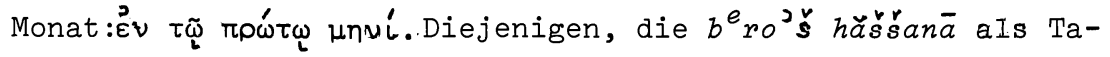
gesbezeiahnung verstehen, verweisen stets auf Lev 25,9, wonach der Beginn des Jubeljahres "im 7. Monat, am 10. des Monats" (V.9a) durch Schøpharblasen angezeigt werden soll; dieser Tag sei dort als Neujahrstag verstanden ${ }^{70}$. Allerdings fehlt in

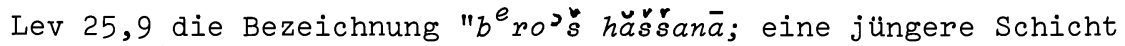
in V.9b71 identifiziert diesen Tag - den 10. VII. - mit dem Versöhnungstag" 72 . Vor allem aber: "Ungeklärt ist, warum der Jahresbeginn auf dem 10. und nicht auf dem 1. des Monats liegt $" 73$.

So ist es durchaus unwahrscheinlich, daß "b ro ’̌̀ hăššanā hier den "Neujahrstag" als den Tag des Jahresbeginnes meint.

Die Bedeutung von $b^{e}$ ro'š hăšsanā ergibt sich, wenn man den Aufbau der Datierung in $\mathrm{Ez} \mathrm{40,1} \mathrm{beachtet.} \mathrm{Er} \mathrm{ist} \mathrm{dreigliedrig:}$ Zunächst wird das Jahr genannt, an dritter Stelle steht der

69 Daneben bezeichnet ro’š hăššanā auch einfach den "Jahresanfang"; RH I, 1 .

70 So z.B. J. HERRMANN, Ezechiel, 263; BEGRICH, Chronologie, 87; GALLING in: BERTHOLET, Hesekiel (HAT), 135; COOKE, Ezekiel, 429; ZIMMERLI, Ezechiel Bd. 2, 982.995. Weitere Vertreter dieser Meinung bei KUTSCH, Herbstfest, 32 Anm. 117.

$71 \mathrm{Vgl}$. dazu ELLIGER, Leviticus, $336.344 \mathrm{f}$.

$72 \mathrm{Vgl}$. Lev 16,29ff.; 23,26-32; Num 29,7-11. Vgl. dazu ELLIGER, Leviticus, $200 \mathrm{ff.318ff.352.} \mathrm{ELLIGER} \mathrm{erwähnt} \mathrm{in} \mathrm{sei-}$ nem Exkurs "Der Versöhnungstag in [Lev] 25,9" (320f.) die Möglichkeit, daß der 10. VII. einmal "Neujahrstag" gewesen sein könnte, (mit Recht) überhaupt nicht.

73 Das stellt mit Recht ZIMMERLI, Ezechiel Bd. 2, 995 fest. Er referiert drei Erklärungsversuche. Aber alle drei sind unhaltbar; denn: Die Tatsache, daß zwischen 1 . und 10. eines Monats eine Frist von nur 9 (und nicht 10 oder 11 1/4) Tagen liegt, schließt Ableitung von ägyptischer Dekadenrechnung (so BARROIS, Manuel d'Archéologie Biblique II, 172) wie Abhängigkeit von der Differenz zwischen Sonnenund Mondjahr (so SNAITH, The Jewish New Year Festival, $131 \mathrm{ff.})$ - diese beträgt 11 1/4 Tage - aus; und Israeliten wie Babylonier haben - da ihre Monate durch den Mond bestimmt waren, nur ganze Monate interkaliert, nie 9 Tage (gegen BEGRICH, Chronologie, $87 \mathrm{f}$. ). 
Tag, dazwischen die Wendung $b^{e}$ ro’s hăšsanā. Diese Dreigliederung entspricht der Mehrzahl der Daten im Ezechielbuch; sie findet sich auch in Ez 1,1; 8,1;20,1;29,1.17; 30,20; 31,1; 32,$1 ; 33,21$, ebenso in $24,1^{74}$. An der zweiten Stelle dieser Daten steht sonst die Monatsangabe. Deren stelle nimmt in


nahe, daß diese Angabe den Monat, in dem sich die Vision ereignet, nennt. Sie gewinnt an Wahrscheinlichkeit, weil in der Tagesangabe der Rückverweis "(am 10.) des Monats" die vorausgehende Nennung des Monats erwarten läßt. be ro šs hăśśanā meint also nicht den Neujahrstag, sondern einen Monat und zwar - von der Bedeutung "Haupt des Jahres" her - doch wohl den ersten Monat. Der Übersetzer der Septuaginta hat in seiner

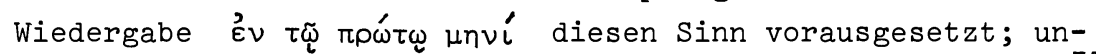
nötig ist die Annahme, ihm habe ein anderer Text - bari ${ }^{2}$ sôn ${ }^{75}$ vorgelegen. Zum Vergleich: In Num 10,10;28,11 bezeichnet ro’̌ hăhodäš "Haupt des Monats" den ersten Tag des Monats; ebenso ist in Ez 40,1 ro'š hăššanā "Haupt des Jahres" - von der nächst höheren Zeiteinheit, dem Monat, gebraucht - der erste Monat. Und wie der Übersetzer von Num 10,10 $b^{e} \mathbf{r a}^{2} \underline{s}_{\hat{e}}$

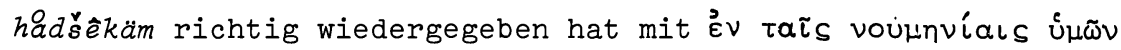
(ebenso Num 28,11), so hat der Übersetzer von Ez 40,1 - wo er mit Recht eine Monatsangabe vermutet - unter ro’š hăšśanā den ersten Monat verstanden.

In $\mathrm{Ez}$ 40,1 ist also aller Wahrscheinlichkeit nach mit der An-

74 Diese Art, bei Daten nicht nur Jahr und Monat (zuletzt in Jer 28,1; 36,9; 41,1 [= II Reg 25,25], sondern auch den Tag eines Ereignisses anzugeben, findet sich in Israel erst vom Exil an; zu den Ezechieldaten treten als alteste Belege II Reg 25,1.3.8. (27) = Jer 39,2; 52,4.6.12 (31); auch Dtn 1,3; Jos 5,10; 4,19 und I Reg 12,32f. sind nicht älter. Vgl. dazu KUTSCH, Herbstfest, $28 \mathrm{ff.}$, sowie ZIMMERLI, Ezechiel Bd.1, $40 \mathrm{ff}$.

75 So BHK mit manchen Kommentaren, aber nicht mehr BHS. 
gabe "am Kopf des Jahres, am 10. des Monats" der 10. I. (= Nisan) des in Frage stehenden Jahres gemeint ${ }^{76.77}$.

Kehren wir nun zu dem Kernproblem von Ez 40,1 zurück. Der Tag und zugleich vor allem auch das Jahr wird durch zwei Fristen mit zwei unterschiedlich lang zurückliegenden Ereignissen verbunden und dadurch bestimmt. Für die Übertragung des Jahres und von da aus dann auch des Tages - in unsere Zeitrechnung "vor Christus" sind zwei Fragen zu beantworten: In welche Jahre unserer Zeitrechnung sind diese beiden Ausgangsereignisse datiert und wie - genauer: von wann an - werden die beiden Fristen gezählt.

Der Blick in die Forschung zeigt, daß die Vision des Ezechiel in großer Einmütigkeit der Exegeten in das "Frühlings"-Jahr 573/2 datiert wird - und das trotz Unterschieden in der Bestimmung des Ausgangspunktes der genannten Fristen und in der Weise, die Jahre zu zählen. Drei Verfahren seien hier diskutiert.

1. FINEGAN - er hatte das Datum hinsichtlich Tag und Monat (wohl richtig) auf den 10. I. bestimmt - beginnt die Zählung der 25 Jahre "Verbannung" der Judäer mit dem Jahr 597/6, also mit dem Jahr, das vier Wochen nach der ersten Einnahme von Jerusalem begann und das FINEGAN auch als das Jahr 1 der Verbannung des Königs Jojachin ansieht. Jahr 25 ist demnach das

76 KUTSCH, Herbstfest, 32ff.; DERS., Chronologie, 273; KRAUS, Gottesdienst in Israel, 85; FINEGAN, Handbook, 211; EICHRODT, Hesekiel. Kap. 19-48, 381; CLINES, Regnal Year Reckoning, 19. - So übrigens ZIMMERLI selbst noch: Ezechiel Bd. 1, 22 .

77 Die Annahme, daß mit dem 10. I. (des Jahres 25) auf das Datum des Beginns der ersten Deportation angespielt sei (so THIELE, The Mysterious Numbers, 162f.; LANG, Ezechiel, 40), entfälit, da Nebukadnezar mit der Verschleppung bereits vor dem 1. I. $597 / 6$ begonnen hat (s. oben 23). 
Jahr 573/2, der 10. I. dieses Jahres nach unserer Rechnung der 28. April $573^{78}$. Die 14 Jahre "nachdem die Stadt geschlagen war" berechnet FINEGAN so: Jerusalem wurde (zum zweiten Mal) von Nebukadnezar erobert am 9. IV., d.h. am 29. Juli $587^{79}$. Von diesem Datum (statt von Neujahr = dem 1. Nisan) aus bestimmt er das erste Jahr "nach" dem Fall der Stadt: Es dauerte vom 29. Juli 587 bis 28. Juli 586. Von da aus das 14. Jahr "nach" der Eroberung ist dann das Jahr 29. Juli 574 bis 28. Juli 573. Und in dieses 14. Jahr fällt auch der über die 25 Jahre "Gefangenschaft" errechnete Termin des 28. April $573^{80}$.

2. Auch ZIMMERLI zählt die 25 Jahre der Gefangenschaft von $597 / 6$ als Jahr 1 ("Ära Jojachins") aus und kommt so ebenfalls auf das Jahr 573/2. Da er aber den 10. VII. (Tischri) als Termin der Vision ermittelt hat, ergibt sich ihm als Datum der 22. Oktober $573^{81}$. Die "Rückrechnung" der 14 Jahre nach dem Fall Jerusalems ${ }^{82}$ erfolgt nicht. Sie käme auf das Jahr 586/5. Hier scheint das 'aḥ̆ar 'a särr (ḩukk ${ }^{e} t \bar{a} h a^{c} \hat{\imath}_{r}$ ) in 40,1aß dahingehend verstanden zu sein, daß als das "1. Jahr nach dem Fall" nicht das Jahr 587/6, sondern das Jahr 586/5 zu gelten habe ${ }^{83}$. 3. VOGT hatte angenommen, daß Jojachin solange König blieb, bis er in Gefangenschaft nach Babel geführt wurde, d.h. bis in den Nisan des Jahres 597/6. Dieses Jahr ist für ihn damit Jahr 1 der Verbannung. Von da aus gezählt, ist deren 25. Jahr das Jahr 573/2. Auf dasselbe Jahr kommt er für den Zeitraum

78 FINEGAN, Handbook, 211 (mit 209); dazu PARKER-DUBBERSTEIN, Babylonian Chronology, 28.

79 Handbook, 206; vgl. PARKER-DUBBERSTEIN, Babylonian Chronology, 28 .

80 Handbook, 211f. - Vgl. auch CLINES, Regnal Year Reckoning, 20.

81 Ezechiel Bd. 2, 995 (mit PARKER-DUBBERSTEIN, Babylonian Chronology, 28).

82 Vgl. dazu Ezechiel Bd. 2, $996 f$.

83 Diese Auffassung vertreten z.B. auch GALLING in: FOHRER, Ezechiel, 222, und JEPSEN, Chronologie, 23 Anm. 18, wenn sie von der Datierung des Falles Jerusalems in den Sommer 587 (also in das Jahr 587/6) auf das Jahr 573/2 kommen. 
von 14 Jahren, "nachdem" Jerusalem geschlagen wurde, indem er auch hier das Jahr des Ereignisses, für VOGT das Jahr 586/5, als erstes Jahr gerechnet hat ${ }^{84}$.

Bei diesen drei Berechnungsarten beobachten wir Übereinstimmungen und Unterschiede. Alle drei stimmen darin überein, daß sie die 25 Jahre Verbannung von 597/6 und die 14 Jahre nach dem Fall der Stadt entsprechend vom Jahr $586 / 5$ aus zählen und so das Jahr 573/2 für die große Tempelvision des Ezechiel erreichen. Und hier liegen die Unterschiede:

1. Für FINEGAN und ZIMMERLI ist das Ausgangsjahr - 597/6 - das erste Jahr nach der Gefangennahme und Deportation Jojachins, für VOGT ist es das Jahr selbst, in dem der judäische König gefangengesetzt und deportiert wurde.

2. FINEGAN und ZIMMERLI bestimmen zwar beide unter Aufnahme der

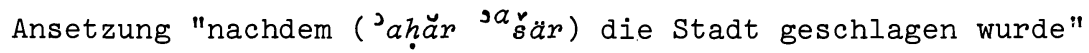
von Ez 40,1b die 14 Jahre von dem Jahr nach der Eroberung. Allerdings ist dabei für ZIMMERLI das Jahr 1 dieser Zählreihe das mit dem 1. Nisan 586 beginnende Jahr, also 586/5, für FINEGAN aber das mit dem Tag der Eroberung beginnende Jahr, also - nach FINEGAN - das Jahr 29. Juli 587 bis 28 . Juli 586.

3. FINEGAN und ZIMMERLI beginnen bei beiden Ausgangsereignissen - bei der Gefangennahme Jojachins wie bei der zweiten Eroberung von Jerusalem - die Zählung mit dem auf das Ereignis folgenden Jahr; VOGT dagegen zählt von dem Jahr an, in das das betreffende Ereignis gefallen ist. Was ist von diesen Verfahrensweisen falsch, was richtig?

1. FINEGANs Bestimmung des Jahres "nach" dem Fall der Stadt vom Tag des Ereignisses an ist in historischen Texten durchaus ungewöhnlich und deshalb auch hier unwahrscheinlich; sie würde am ehesten etwa in Schuldverträge passen.

2. Die Datierung der Verhaftung und Deportierung des Jojachin

84 Die neubabylonische Chronik, 96 Anm. 2. 
in das Jahr 597/6 und die der zweiten Eroberung von Jerusalem in das Jahr $586 / 5$ sind nicht zu halten ${ }^{85}$.

3. Von wann an werden in Israel (darüber hinaus im Alten Orient) Fristen "nach" einem bestimmten Ereignis gezählt? Konkret: Der König Jojachin ist in der Zeit zwischen 2. und 29. Adar des Jahres $598 / 7$ gefangengesetzt und deportiert worden - welches ist das Jahr 1 seiner Gefangenschaft: das Jahr 598/7 oder das Jahr 597/6? Ein Blick auf die sonst belegte Zählweise und den einschlägigen Sprachgebrauch gibt Aufschluß.

a) Über die Belagerung der Stadt Samaria durch die Assyrer unter Salmanassar V. macht das Alte Testament in II Reg 18,9-10 folgende Angaben: Die Belagerung begann im 7. Jahr des israelitischen Königs Hosea $=4$. Jahr des judäischen Königs Hiskia (V.9) ${ }^{86}$. Salmanassar hat die stadt eingenommen "am Ende von 3 Jahren" 87 (V.10a). Nach unserer Zählweise würde diese Formulierung bedeuten, daß die Stadt nach (rund) 3 Jahren, d.h. im 10. Jahr des Hosea ( $=7$. Jahr des Hiskia) in die Hände der Assyrer gefallen ist. V.10b aber nennt als Jahr der Eroberung das 9. des Hosea ( $=6$. des Hiskia). Daraus ergibt sich: In Israel hat man anders gerechnet. Das Jahr des ersten Ereignisses - Beginn der Belagerung - wird mitgezählt; die "3" Jahre bis zur Eroberung haben nur (rund) 2 Jahre gedauert.

b) Ein zweites Beispiel gibt das Neue Testament. Nach den Synoptikern wird der Menschensohn "am dritten Tag" - so Mt 16,21; 17,$23 ; 20,19$ bzw. Lk 9,22 und 18,33 88 - , nach Mk 8,31; 9,31;


Auch bei dieser Tageszählung ist der 1. Tag mit dem Tod des Menschensohns als Ausgangspunkt mitgezählt ${ }^{89}$.

85 S. oben $19 \mathrm{ff}$.

$86 \mathrm{Zu}$ diesem Synchronismus vgl. oben 28.

87 miqqe șe šaloš šan $̂$, meist wiedergegeben mit "nach 3 Jahren".

88 Ebenso I Kor 15,4.

$89 \mathrm{Vgl}$. etwa GNILKA, Markus Bd. 2, $15 \mathrm{f} .53 \mathrm{f} .96 \mathrm{f}$, , sowie LEHMANN Auferweckt am dritten Tag nach der Schrift; McARTHUR, "On the Third Day". 
Aus diesen Belegen ergibt sich zweierlei:

1. Bei derartigen Fristbestimmungen wird das Jahr (bzw. der Tag) des Ausgangsereignisses mitgezählt. Bei der Zählung der Verbannungsjahre ist also das erste Jahr der Zählung das der Gefangennahme des Königs, d.h. das Jahr 598/7, nicht, wie zumeist angenommen, das Jahr danach, d.h. das Jahr 597/6.

2. Daß Samaria "am Ende von 3 Jahren" oder "nach 3 Jahren" erobert wurde, besagt nichts anderes als "drei Jahre nach dem Beginn der Belagerung". Wenn aber, wie aufgezeigt, bei dieser Datierung das Jahr des Beginns der Belagerung mitgezählt ist, dann rechnet auch in Ez 40,1 bei der Angabe "im 14. Jahr nach dem Fall der Stadt" das Jahr dieses Ereignisses mit, es ist das Jahr $587 / 6$.

Im Blick auf die behandelten drei Rechensysteme zeigt sich: FINEGAN und ZIMMERLI sind zwar von den richtigen Daten ausgegangen: Gefangennahme und Deportierung Jojachins im Jahr 598/7, zweite Eroberung Jerusalems im Jahr 587/6, haben aber mit der Zählung der Jahre bis zum Zeitpunkt der Tempelvision 25 bzw. 14 Jahre - in unterschiedlicher Weise - ein Jahr zu spät mit der Zählung eingesetzt. VOGT hat die beiden Ereignisse um je ein Jahr zu spät angesetzt (597/6 bzw. 586/5), hat aber beide Male richtig das Jahr des jeweiligen Ereignisses als Jahr 1 gezählt. So liegt bei allen dreien das Jahr der Tempelvision um ein Jahr zu spät. Zählt man die 25 Jahre der Verbannung von 598/7 und die 14 Jahre "nach" der Eroberung von Jerusalem von 587/6 (als Jahr 1) aus, ergibt sich als Jahr der Tempelvision von Ez $40 \mathrm{ff}$. das Jahr 574/390. Der genaue Tag der Vision war also der 10. I. = 10. April $574^{91}$.

90 So KUTSCH, Chronologie, 274 Anm. 25. - Dieses Ergebnis entspricht also genau dem "plain sense" von Ez 40,1; zu CLINES, Regnal Year Reckoning, 19 Anm. 39.

91 Vgl. dazu PARKER-DUBBERSTEIN, Babylonian Chronology, 28. 


\section{2. $\operatorname{Ez~33,21~}$}

Zweckmäßigerweise setzen wir die Analyse der Daten im Ezechielbuch mit den beiden Stellen fort, an denen ebenfalls die Jahre von dem Beginn der Verbannung (galut) aus gezählt werden: 33,21 und 1,2. Wir wenden uns zunächst 33,21 (mit V.22) zu:

(21) Und es geschah im 12. Jahr im 10. Monat am 5. des Monats unserer Verbannung ( $\tau^{e}$ galutenû), da kam ein Entronnener aus Jerusalem zu mir mit der Nachricht: Die Stadt ist eingenommen. (22) Es war aber die Hand Jahwes am Abend vor der Ankunft des Entronnen über mich gekommen. Er (Jahwe) aber öffnete meinen Mund auf den Zeitpunkt hin ${ }^{92}$, da er (der Entronnene) am Morgen zu mir kam. Und mein Mund wurde geöffnet, und ich blieb nicht mehr stumm.

In dem kurzen Bericht erfahren wir, daß ein Bote dem unter den Verbannten in Babylonien lebenden Ezechiel die Nachricht vom Fall Jerusalems bringt. Der Prophet hat durch ein von Jahwe gewirktes Verstummen - wohl vom Abend des Vortages an 93 das auf den Eingang der Nachricht hin zu Ende ist, eine gewisse Vorbereitung erfahren.

Der Eingang der Mitteilung ist datiert auf den 5. X. des 12 . Jahres der Verbannung. Aus dieser Ansetzung ergibt sich folgendes Problem. Jerusalem wurde nach II Reg 25,2ff. und Jer 52,5ff. am 9.IV. des 11. Jahres des Zedekia erobert. Wenn der Überbringer der Nachricht am 5. X. des 12. Jahres der Verbannung - das nach der verbreiteten Anschauung dem Jahr nach dem 11. Jahr des Zedekia entspricht 94 - in Babylonien bei Ezechiel eingetroffen ist, war er rund 18 Monate oder rund ein Jahr und $51 / 2$ Monate nach unserer Zeitrechnung unterwegs. Das ist - auch bei Berücksichtigung kriegerischer Zeitläufe und

92 So mit der Übersetzung von ZIMMERLI, Ezechiel Bd. 2, 810.

93 Vgl. ZIMMERLI, Ezechiel Bd. 2, 813.

$94597 / 6$ = Jahr 1 Zedekia = Jahr 1 der ersten Exilierung; s. oben 38 . 
unsicherer Wegeverhältnisse - mit Sicherheit zu viel. Man könnte für den Weg von Jerusalem bis Tel Abib, dem Aufenthaltsort des Ezechiel, mit einer Frist von etwa 6 Mondmonaten oder rund 175 Tagen rechnen, nicht aber mit 18 Mondmonaten. Wir diskutieren drei in der neueren Literatur herausgearbeitete Möglichkeiten, den tatsächlichen Sachverhalt zu ermitteln, und fügen als vierte die sich aus dem hier bisher Erarbeiteten ergebende Lösung an 95 .

1. und 2. Die beiden ersten hier zu nennenden Forscher, MALAMAT und VOGT, gewinnen diese Frist von ca. 6 Monaten unter Beibehaltung der Angabe des "12." Jahres der Verbannung mit Hilfe ihrer chronologischen Systeme. Beide datieren die Eroberung der stadt Jerusalem auf den 9. IV. $586=18$. Juli 586, die Ankunft des Entronnenen demnach auf den 5 . X. $586 / 5=8$. Jan. $585^{96}$. Für MALAMAT fällt dieses Datum a) in das Jahr nach dem 11. Jahr des Zedekia - dieses (spätere) Jahr begann mit dem 1. VII. 586 - , b) in das 12. Jahr der Verbannung - dieses begann mit dem 1. I. 58697. Nach VOGT gehört der 5. X. in das 11. Jahr des Zedekia, das dem 12. Jahr der Verbannung entspricht: Beide beginnen mit dem 1. I. 586 ${ }^{98}$. Bei beiden Autoren liegen so beide Daten innerhalb eines Kalenderjahres, $586 / 5$, so daß sich für den Weg des der Katastrophe Entronnenen die Frist von knapp 6 (Mond-) Monaten ergibt.

95 Es erübrigt sich, auf die etwa von BERTHOLET, Hesekiel (HAT), 117, vertretene These einzugehen, nach der in Ez 33,21 eine "irrtümliche Wiederholung" des (nun schon verschriebenen) Datums von 32,17 vorliege. Vielmehr habe der "Flüchtling" dem sich in einem judäischen Ort in der Nähe Jerusalems aufhaltenden (vgl. a.a.0. $89 \mathrm{zu} \mathrm{Ez} \mathrm{24,26)}$ Propheten noch am Tage des Ereignisses die Kunde vom Fall Jerusalems überbracht. Voraussetzung für die Darstellung ist die These, daß der Prophet bis zum Untergang von Jerusalem im Jahr 587 in der stadt gewirkt habe.

96 So MALAMAT, The Twilight of Judah, $144 \mathrm{f}$. - Die Datierungen in unsere Zeitrechnung nach PARKER-DUBBERSTEIN, Babylonian Chronology, 28.

97 The Last Kings of Judah, 149; The Twilight of Judah, $144 \mathrm{f}$. - So auch FREEDY-REDFORD, The Dates in Ezekiel, $466 \mathrm{f}$. S. Tabelle IV unten 75 .

98 Jahr der Eroberung, 228. - S. Tabelle IV unten 75. 
Beide Berechnungen scheitern aber an ihren Voraussetzungen. MALAMAT muß, um mit dem 11. Jahr des Zedekia in das Jahr Herbst $587 / 6 \mathrm{zu}$ gelangen, für das Jahr Herbst 609/8 zwischen das letzte (31.) Jahr des judäischen Königs Josia (= Herbst 610/9 nach MALAMAT) und das 1. Jahr des Jojakim (= Herbst 608/7 nach MALAMAT) ein "Akzessionsjahr" für Jojakim"9 bzw. ein "Jahr 1" für Joahas ${ }^{100}$ einschalten; dies ist aber nach dem nachdatierenden System, die Königsjahre zu zählen, unmöglich $^{101}$. Zudem schließen die beiden fixen Synchronismen mit Angaben der babylonischen Chronik - Tod des Josia im Sommer (wohl im 3. Monat) 609 sowie erste Einnahme von Jerusalem durch Nebukadnezar am 2. Adar des 7. Jahres des Nebukadnezar, also am 16. März 597 - eine Herbstjahr-Rechnung für die ausgehenden Königsjahre in Juda aus ${ }^{102}$.

Andererseits rechnet VOGT ${ }^{103}$ für das Jahr zwischen dem 11. Jahr des Jojakim (= Frühahr 598/7) und dem 1. Jahr des Zedekia (nach VOGT $=596 / 5)$ mit einem Akzessionsjahr ( $=\mathrm{Jahr} 0$ ) für Zedekia ( $\left.=597 / 6^{104}\right)$ - was wiederum dem nachdatierenden System widerspricht.

So scheiden die Erklärungen von MALAMAT und VOGT für das Datum des 5. X. Jahr 12 der Verbannung und die seit der Eroberung Jerusalems bis dahin verstrichene Zeit aus.

3. Um die durch Ez 33,21 (scheinbar) angegebene Frist von

18 Mondmonaten auf 6 Monate zu reduzieren, wird von zahlreichen

99 So A New Record, 256; The Last Kings of Judah, 147 Anm. 21 unter (b).

100 So The Twilight of Judah, 127 Anm. 9 unter (a) und die Tabelle 144 (vgl. Tabelle I unten 72).

$101 \mathrm{~S}$. oben $17 \mathrm{ff}$.

$102 \mathrm{~S}$. oben $16 \mathrm{ff}$.

$103 \mathrm{Jahr}$ der Eroberung, 228.

$104 \mathrm{Vgl}$. Tabelle IV hier 75. 
Autoren die Angabe des "12." Jahres in "11." geändert ${ }^{105}$. Textkritisch ist diese Änderung allerdings nur schwach abgesichert ${ }^{106}$. So ist ihr auf jeden Fall eine Erklärung des Textes vorzuziehen, die den MT beibehält, aber die bei MALAMUT und VOGT auftretenden Probleme nicht hat.

4. Die Erklärung folgt aus den Ergebnissen, die wir bisher gewonnen haben. Nach den alttestamentlichen Quellen und der babylonischen Chronik ist Jojachin noch Ende des Jahres 598/7, im Zeitraum vom 2. Adar bis zum Ende dieses Monats, abgesetzt und nach Babylonien in die Verbannung in Marsch gesetzt worden; zur selben Zeit - also noch im Adar 598/7 - wurde Zedekia auf den judäischen Thron gesetzt. Nach alttestamentlicher Rechnungsweise bedeutet das, daß der Rest des Jahres 598/7 für die Verbannung des Jojachin (und der mit ihm Verschleppten) als "Jahr 1" gilt, für den neuen König aber (nur) als "Anfang der Regierung" ("Akzessionszeit")107. Das Jahr 597/6 ist Jahr 2 der Verbannung und Jahr 1 des Zedekia ${ }^{108}$. Das für den Untergang Jerusalems ermittelte Jahr 587/6 109 ist also Jahr 11 des Zedekia und Jahr 12 der Verbannung ${ }^{110}$. Eroberung der stadt und Eintreffen der Nachricht davon bei den Exulanten liegen also in einem Jahr, 587/6: Die Katastrophe ereignete sich nach II Reg 25,3f. = Jer 52,6f. am 9. IV. 587/6 = 29. Juli 587; die Kunde davon traf nach Ez 33,21 bei dem Propheten ein am 5. $X \cdot 587 / 6=19$. Januar 586 111 . Das Datum von Ez 33,21 ist

105 So etwa J. HERRMANN, Ezechiel, 211; FOHRER, Ezechiel, 187 ; EICHRODT, Hesekiel. Kap. 19-48, 316f.; ZIMMERLI, Ezechiel Bd. 2, 810.812. Auch CLINES, Regnal Year Reckoning, $19 f$. erwägt die Änderung in das 11. Jahr "as a serious alternative" $\mathrm{zu}$ dem MT.

106 So mit Recht FREEDY-REDFORD, The Dates in Ezekiel, 466 Anm. 25. Nur 8 Mss., die lukianische Rezension der LXX und der syrer bieten das 11. Jahr. So ist die Konjektur auch nicht in BHK und BHS übernommen. Anders CLINES, Regnal Year Reckoning, $20 \mathrm{Anm}$. 40.

$107 \mathrm{~S}$. oben $40 \mathrm{bzw} .22$.

$108 \mathrm{Vgl}$. Tabelle IV unten 75.

$109 \mathrm{~s}$. oben 30 .

110 So bereits KUTSCH, Chronologie, 274.

111 Cf. PARKER-DUBBERSTEIN, Babylonian Chronology, 28. 
also so, wie es der MT bietet, korrekt. Es bestätigt umgekehrt, daß das "1. Jahr der Verbannung" mit 598/7 richtig angesetzt ist.

Nach Esr 8,31 ist Esra mit seinem Gefolge am 12. I. des 7. Jahres des Artaxerxes in Babylonien aufgebrochen und nach Esr 7,9 am 1. V. desselben Jahres in Jerusalem angekommen; er hat also für diese Strecke etwas über $31 / 2$ Mondmonate benötigt ${ }^{112}$. Im Vergleich dazu sind die knapp 6 Mondmonate, die in Ez 33,21 dem Judäer für den Weg durch das von babylonischen Feinden beherrschte Land zugeschrieben sind, durchaus akzeptabel. Das Datum von $\mathrm{Ez} 33,21$ hat also auch in dieser Hinsicht alle Wahrscheinlichkeit für sich.

\section{Ez 1,1-2}

Bereits der Beginn des Ezechielbuches in 1,1-2 gibt ein Datum nach der Verbannung, die hier - am Anfang des Buches - ausdrücklich als die galût "des Königs Jojachin" bezeichnet ist. Wir vergegenwärtigen uns den Text, wobei wir den V. 3 in die Übersetzung mit einbeziehen.

(1) Und es geschah im 30. Jahr im 4. (Monat) am 5. (Tag) des Monats - ich war unter der Verbanntenschaft am Fluß Kebar - , da öffnete sich der Himmel, und ich sah Gottesgesichte. (2) Am 5. des Monats, das ist das 5. Jahr der Verbannung des Königs Jojachin, (3) , 113 erging das Wort Jahwes an Ezechiel, den Sohn des Busi, den Priester, im Lande der Chaldäer am Fluß Kebar. Und es kam über 'mich'114 (dort) 115 die Hand Jahwes.

$112 \mathrm{Zu}$ weiteren Erwägungen über Marschzeiten auf diesem Wege vgl. CLINES, Regnal Year Reckoning, 34.

113 Der inf.abs. hajo resultiert wohl aus einer Dittographie von hajā; vgl. LXX,Targum, Vulgata und etwa ZIMMERLI, Ezechiel Bd. 1, $3 f$.

114 MT: (über) ihn. Zur Konjektur vgl. etwa ZIMMERLI, Ezechiel Bd. 1, 4.22.

115 šam ist hier vielleicht sekundär; vgl. ZIMMERLI, Ezechiel Bd. 1, 4 . 
In seiner jetzigen Form enthält dieser Text zwei Zeitangaben: "im 30. Jahr im IV. am 5. des Monats" in V. 1aa und "am 5. des Monats - das ist das 5. Jahr der Verbannung des Königs Jojachin" in V. 2. Die Einleitung der zweiten Jahresangabe mit $h \hat{\imath}^{2}$ erweckt den Eindruck, daß dieses "5. Jahr der Verbannung" dem zuvor in V.1 genannten "30. Jahr" entspricht, daß also ein Synchronismus vorliegt ${ }^{116}$. Die Angabe "am 5. des Monats" in V. 2 könnte geradezu eine Aufnahme derselben Formulierung in V.1aa sein. Falls dies zutrifft ${ }^{117}$, liegt die Annahme nahe, daß für das Datum in V.2b auch die Monatsangabe - "im 4. (Monat)" - aus V.1 gilt. Für das 5. Jahr der Verbannung Jojachins ergibt sich - da die Zählung der Verbanntenjahre ein Jahr vor der "Königschronologie" des Zedekia beginnt - nicht das Jahr $593 / 2^{118}$, sondern das Jahr 594/3 119 ; das genaue Datum von V.2 - 5. IV. $594 / 3$ - ist in diesem Fall der 13. Juli $594^{120}$. Nicht befriedigend erklärt ist bisher das Datum von V.1. Von welchem Ausgangsdatum aus sind die "30 Jahre" gezählt? Die Deutungsversuche sind zahlreich ${ }^{121}$. Sie verteilen sich im wesentlichen auf zwei Gruppen ${ }^{122}$.

1. Man hat den Text geändert, indem man

a) die Zahl "30" in "13" korrigiert hat, so daß man das Jahr 593 als das 13. Jahr des Nebukadnezar ermittelte 123 bzw. von 597 als dem (vermuteten) Beginn der Gefangenschaft des Jojachin aus auf das Jahr 585 (= ein Jahr nach der - falsch

$116 \mathrm{Zu}$ mit $h \hat{\imath}^{\mathrm{J}}$ eingeleiteten Synchronismen vgl, oben $27 \mathrm{ff}$. $117 \mathrm{Vgl}$. dazu unten 50.

118 So die fast ausnahmslos vertretene Auffassung.

119 So auch schon BEGRICH, Chronologie, 207 und PROCKSCH, Theologie, 309.

120 Cf. PARKER-DUBBERSTEIN, Babylonian Chronology, 28.

$121 \mathrm{Vgl}$. FOHRER, Hauptprobleme, $110 \mathrm{ff}$.

122 Wir sehen hier ab von den Versuchen, die Zahl 30 aus einer anderen Zeit, etwa der des Königs Manasse, zu erklären.

123 ROTHSTEIN, Jeremia, 873 Anm.b; SELLIN, Geschichte II, 39. 
angesetzten - Eroberung Jerusalems 586) käme ${ }^{124}$, was beide Male jedenfalls den Termin des "5. Jahres" der Verbannung des Jojachin von Ez 1,2 verfehlt;

b) statt "30" "3" gelesen hat ${ }^{125}$;

c) das "5." Jahr von Ez 1,2 als in 1,1 ursprünglich annimmt und mit mancherlei Begründungen eine spätere Versetzung nach V.2 und eine Neueinfügung des "30." Jahres in V.1 zu erklären versucht ${ }^{126}$;

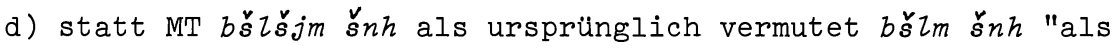
ein Jahr vollendet war", womit ein Jahr gemeint sei, das auf ein in der Autobiographie des Propheten berichtetes Ereignis gefolgt sei ${ }^{127}$.

2. Man hat die "30 Jahre" auf bestimmte Ären bezogen, als deren Ausgangspunkt man annahm

a) die Auffindung der Gesetzesrolle bzw. die Kultreform Josias in dessen 18. Regierungsjahr (II Reg 22,3ff.) ${ }^{128}$ - von 622/1 aus käme man aber auf 593/2, nicht auf 594/3; vor allem ist die Zählung des Jahres nach einer solchen "Ära" sonst unbekannt,

b) den Regierungsbeginn eines der neubabylonischen Herrscher: des Nabopolassar ${ }^{129}$ oder des Nebukadnezar ${ }^{130}$ - aber solche

124 SO BERTHOLET, Hesekiel (HAT), 3.

125 So HERNTRICH, Ezechielprobleme, 63f., der das "3. Jahr" des Zedekia meint, dieses von Herbst 596/5 = Jahr 1 aus zählt und damit ebenso auf den 5. Monat ( $=\mathrm{ca}$. August/ September 593) kommt wie mit dem 5. Jahr der galüt, das er von Frühjahr 597/6 aus errechnet; ebenso WHITLEY, The 'Thirtieth' Year, 329f., der mit dem "3. Jahr" das der Verbannung meint und der so von 597/6 als Jahr 1 aus auf $595 / 4$ kommt, ohne einen Ausgleich mit dem "5. Jahr" von $\mathrm{Ez}$ 1,2 zu erwägen.

126 So u.a. BERTHOLET, Hesekiel (KHC), 2; Fohrer, Hauptprobleme, 116; DERS., Ezechiel, 5; ZIMMERLI, Ezechiel Bd. 1,43.

127 TUR-SINAI, The Double Dating of Ezekiel i, 1-3, 5-7.110.

128 So u.a. J. HERRMANN, Ezechiel, 10.

129 So u.a. SMEND, Ezechiel, z. St.

130 So ROTHSTEIN, Jeremia, 873 Anm. b; SELLIN, Geschichte, 39. 
Ären sind sonst durch eine entsprechende Angabe angezeigt ( $\mathrm{z} . \mathrm{B}$. II Reg 24,12); zudem käme man für Nabopolassar von 625/4 als Jahr 1 auf 596/5 und nicht auf 594/3, für Nebukadnezar auf 575/4, weshalb dann auch die "30" in "13" geändert werden muß ${ }^{131}$, was wiederum unbrauchbar auf 592/1 führt.

c) Hierher gehört auch die Annahme, die Zahl "30" in Ez 1,1 bezeichne das Lebensalter des Propheten bei Beginn seiner Wirksamkeit ${ }^{132}$. Ezechiel wäre im "5. Jahr der Verbannung des Jojachin" 30 Jahre alt gewesen, also (von 594/3 aus gerechnet) im Jahr $623 / 2$ geboren. Eine solche "Bestimmung eines einzelnen Lebensjahres" ist im Alten Testament ohne Analogie ${ }^{133}$, so daß diese Deutung wenig Wahrscheinlichkeit für sich hat.

d) Dieses Bedenken gilt auch gegen die Deutung der Jahresangabe von $E z$ 1,1 als 30. Lebensjahr des Jojachin ${ }^{134}$. Die Jahre des Jojachin werden im Alten Testament gerade nicht nach seiner Geburt, sondern nach seiner galût gezählt (II Reg 25,27 = Jer 52,31 - und gerade Ez 1,2!).

e) So hat der Sachverhalt, daß die Daten im Ezechielbuch sich sonst auf die Verbannung des Jojachin beziehen ${ }^{135}$, schließlich dazu geführt, daß man auch das 30. Jahr von V.1 auf diese "Ära" bezogen hat 136 .

131 ROTHSTEIN, Jeremia, 873 Anm. b; SELLIN, Geschichte, 39.

132 So schon Origenes; in neuerer Zeit etwa KRAETZSCHMAR, Ezechiel, $1 \mathrm{ff}$; BUDDE (zuletzt in:) Zum Eingang des Buches Ezechiel, 20-41 (mit der Änderung von šana "Jahr" in šanaj "[im 30.I meiner Jahre"); EICHRODT, Hesekiel. Kap. 1-18, 3; TAYLOR, A Reconsideration (mit dem - nichts entscheidenden - Hinweis auf die formale Datierungsparallele in Gen 8,13 ).

133 BUDDE, Zum Eingang des Buches Ezechiel, 29.

134 So SNAITH, The Dates in 'Ezekiel'.

135 Zur Ausnahme Ez 24,1 s. unten 61ff.

136 So MERX, Der Werth der Septuaginta, 73; BERRY, The Title of Ezekiel (1,1-3), 54-57; ALBRIGHT, The Seal of Eliakim, 77-106, HOWIE, The Date and Composition of Ezekiel, z.St.; PROCKSCH, Theologie, 309 Anm. 2; LANG, Ezechiel, 33 . 
Gegen die Deutung des Datums yon Ez 1,1 auf das 30. Jahr der Verbannung des Jojachin kann man nicht anführen, daß "the flow of the introduction tells against this" ${ }^{137}$; denn der offensicht liche Neueinsatz in V.2.3a gegenüber V.1 mit einem zweiten Datum und mit der nochmaligen Nennung des "Flusses Kebar" in V.3a zeigt, daß von einem "Fluß der Einleitung" nicht zu reden ist. Problematisch sind allerdings die Annahmen des Verlustes oder der Umstellung eines Ezechielwortes aus dieser Zeit ${ }^{138}$ oder Umstellungen und Änderungen im Text von Ez 1,1-3 (auch wenn die Jahresangaben "30." und "5." beibehalten werden) 139 und die Vermutung, das "30. Jahr" sei "the date of original publication by the prophet"140. Nur: Alle diese - berechtigten - Bedenken treffen eine Rekonstruktion des Textes von Ez 1,1-3 sowie die bisherigen Versuche zu erklären, welches Prophetenwort oder sonstige Ereignis mit diesem "30. Jahr" in Verbindung zu bringen sei; sie treffen aber nicht den Kern der Sache: daß Ez 1,1 das 30. Jahr der Ära "galût des Jojachin" meine.

Vergleicht man die Datierung von Ez 1,1 mit den übrigen Daten im Ezechielbuch, dann zeigt sich leicht, daß die Formulierung von Ez 1,1 mit den Daten übereinstimmt, die eine Jahreszahl von 11 an aufwärts nennen. Nehmen wir 30,20 zum Vergleich:

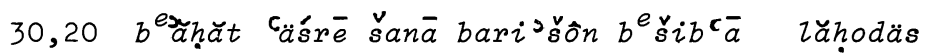

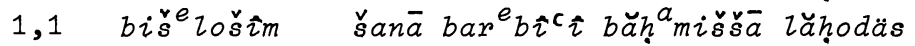
Die Jahreszahl, mit $b$ eingeführt, im mask. der Kardinalzahl 141

137 So TAYLOR, A Reconsideration, 119.

138 So MERX, Der Werth der Septuagina, 73; dagegen FOHRER, Hauptprobleme, 114.

139 So ALBRIGHT, The Seal of Eliakim, $96 \mathrm{f} . ;$ dagegen FOHRER, Hauptprobleme, 114; WHITLEY, The 'Thirtieth' Year, 330 Anm. 2.

140 So ALBRIGHT, The Seal of Eliakim, 97; dagegen ZIMMERLI, Ezechiel Bd. 1, 43.

$141 \mathrm{Vgl}$. dazu die Jahreszahlen bis 10: "Im 6. (7., 10.) Jahr" (Ez 8,1; 20,1; 29,1) mit Ordinalzahlen. - Vgl. dazu GK $\$ 97 d-f$ und $\$ 98 a . b$. 
danach die Bezeichnung "Jahr"; für den Monat lediglich die Zahl mit $b$; der Tagesangabe in fem. Kardinalzahl mit $b$ der Vermerk "des Monats" beigefügt. Da weder andere Ären für das 30. Jahr von 1,1 wahrscheinlich zu machen sind noch eine Textänderung sinnvoll ist, ist angesichts dieser Entsprechung zu den übrigen Zeitangaben im Ezechielbuch ${ }^{142}$ auch für die Datierung von 1,1 von der sonst hier üblichen "Ära" der Verbannung des Jojachin auszugehen. Hier ist demnach der 5. IV. des 30. Jahres der galut Jojachins gemeint, das ist der 5. Juli des Jahres 569; dieses entspricht dem 36. Jahr des Nebukadnezar.

Aus dieser Feststellung ergibt sich: Die beiden Jahresangaben in Ez 1,1 und 2 bezeichnen nicht - wie es der Synchronismus (vgl. das $h \hat{\imath}$ ) in V.2) will - dasselbe Jahr, sondern meinen zwei verschiedene Jahre ${ }^{143}$ : das 5. und das 30. Jahr ein und derselben "Ära". Das erste ist das früheste, das zweite das späteste Datum. So umschreiben diese beiden Angaben - soweit unsere Quellen reichen - die Wirkungszeit des Propheten Ezechiel: Es ist die Zeit von $594 / 3$ bis $569 / 8$ v. Chr.

Ein Problem besteht darin, daß das Datum von V.2 nur den Tag "des Monats" nennt, nicht aber auch diesen selbst. Daß die Monatsangabe fehlt, begegnet auch sonst im Ezechielbuch: 26,1 (1.?.11) und 32,17 (15.?.12). Trotzdem ist zu fragen, welcher Monat in 1,2 gemeint ist. Daß in V.2 derselbe Tag wie in V.1 genannt ist, erweckt den Eindruck, daß damit in V.2 Tages- und Monatsdatum von V.1 "aufgenommen" werden sollen. Man kann mit dieser Möglichkeit rechnen, ihre Richtigkeit aber nicht beweisen.

Der hier vertretenen Anschauung, daß in 1,1-3 zwei verschiedene Einleitungen zu je einem eigenen Ereignis ineinandergeflochten sind, steht etwa die Annahme gegenüber, daß am Anfang von Kap. 1 "eine bearbeitende Hand eingegriffen und die ursprünglich in 1 stehende, heute in der Glosse nachgetragene Jahres-

$142 \mathrm{Zu}$ diesen vgl. ZIMMERLI, Ezechiel Bd. 1, 42.

143 Damit rechnen auch diejenigen, die die "30" in das 13. Jahr der galût des Jojachin ändern. S. dazu oben $46 f$. 
angabe durch die Einfügung der 30 Jahre verdrängt hat" ${ }^{144}$. Doch hat diese Deutung von vornherein deshalb geringere Wahrscheinlichkeit für sich, weil hier mit einer umständlichen Entwicklung gerechnet werden muß: 1. Ersetzung des ursprünglichen Datums des 5. Jahres durch das 30.; das erste Datum bleibt (wo?) erhalten; 2. das ursprüngliche Datum wird als "Glosse" in V.2 nachgetragen. Warum hat der Interpolator von V.2 den Nachtrag so ungeschickt in den Text eingeschoben, statt ihn an den Anfang zu stellen? Zudem: Wie kommt es zur zweimaligen Ortsangabe "am Fluß Kebar" in V.1a und 3a? Daß demgegenüber die Zeitangabe von V.2 (in ihrer ursprünglichen Form) mit V.3a von Hause aus zusammengehört, lehrt der Vergleich mit den Überschriften in Hag 1,1 und Sach 1,1. Hag 1,1 nennt Jahr, Monat und Tag des persischen Königs Darius und fährt fort: "... Es erging das Wort Jahwes durch den Propheten Haggai am ...". Sach 1,1 gibt zwar nur Monat und Jahr des Darius an, entspricht aber im folgenden Ez 1,2.3a näher: "Im 8. Monat im 2. Jahr des Darius erging das Wort Jahwes an Sacharja, ', 145 den Sohn des Iddo, den Propheten, folgendermaßen." Gegenüber dieser Grundform weicht Ez 1,2 insofern ab, als hier nur der Tag genannt, die Jahresangabe aber in Form eines Synchronismus, mit $h \hat{\imath}^{2}$ eingeleitet, angeschlossen ist. Aber die Änderung in diese Form erklärt sich aus der sekundären Voranstellung des Datums von V.1, mit dem nun die alte Angabe des 5. Jahres koordiniert, d.h. im Sinne des Kompilators gleichgestellt werden sollte. Mit dem so rekonstruierten ursprünglichen Wortlaut. von V.2 mit V.3a haben wir - vgl. Hag 1,1; Sach 1,1 - eine eigenständige Überschrift vor uns ${ }^{146}$. Sie leitet, wie die Wortereignisformel in V.3a zeigt, ein Wort Jahwes an den Propheten ein.

144 ZIMMERLI, Ezechiel Bd. 1, 43 (man wird um diese Annahme "kaum herumkommen"), nach FOHRER, Hauptprobleme, 116.

145 Zur Streichung von "Sohn des Berechja" vgl. die Kommentare.

$146 \mathrm{Ez} \mathrm{1,2}$ und 3 a können also nicht voneinander getrennt werden. Anders FOHRER, Ezechiel, 5; ZIMMERLI, Ezechiel Bd. 1, 22. 
Dieser Überschrift ist im jetzigen Textbestand in V.1 die datierte Einleitung zu einer Vision vorangestellt. Auf das (vollständige) Datum folgt nach einer Parenthese, in der - für den Anfang eines Prophetenbuches ganz ungewöhnlich! - der Prophet selbst in erster Person, ohne daß sein Name genannt wird, seinen "Standort", die Verbanntenschaft am Fluß Kebar, angibt, der Bericht über eine Vision: "Da öffnete sich der Himmel, und ich sah Gottesgesichte." Der Visionsbericht fährt in V.4 fort mit den Worten "und ich sah, und siehe ..." Ein Vergleich mit 8,1, wo zwischen Datum mit parenthetischer "Standortbestimmung" - "ich saß in meinem Hause, und die Ältesten von Juda saßen vor mir" - und Beginn des Visionsberichtes in V.2: "und ich sah und siehe..." die Aussage "und es fiel die Hand des Allherrn Jahwe auf mich" gestellt ist, lehrt für den Anfang von Kap. 1, daß der vor der Einleitung des Visionsberichtes in V.4 in V.3b stehende Satz: "Und es kam (dort) die Hand Jahwes über mich" ebenfalls zum Visionsbericht (und nicht zur Wortereignisformel in V.3a) gehört. Die zweite Utberschrift in 1,1-3 besteht also aus V.1 und $3 \mathrm{~b}$.

Die Annahme, daß in Ez 1,1-3 zwei ursprünglich selbständige "Überschriften" miteinander verflochten sind - 1,2.3a und 1,1.3b - löst die Probleme des Textes einfacher und damit besser als die bisherigen Auslegungen. Daß diese Analyse von 1,1-3 richtig ist, bestätigt der Text von 1,4-3,11. Den zwei Überschriften entsprechend und von Hause aus an diese anschließend lassen sich hier deutlich zwei "Ereignisse" herausheben und voneinander absetzen. Es sind dies die Thronwagenvision in 1,4-28a und der Berufungsbericht in 1,28b;2,1 3,11.147. Beide Texte haben je eigene Themen, die von Hause

147 Die Trennung von Thronwagenvision und Berufungsbericht ist schon früher in unterschiedlicher weise mit verschiedenen Ausgangspunkten und Zielrichtungen sowie mit unterschiedlicher Abgrenzung vorgenommen worden; vgl. dazu z.B. ZIMMERLI, Ezechiel Bd. 1, 13ff., wo jetzt auch LANG, Ezechiel, $19 \mathrm{ff}$. nachzutragen ist. Ihnen gegenüber rechnet ZIMMERLI, Ezechiel.Bd. 1, $16 \mathrm{ff}$, wiederum damit, daß Thronwagen- und Berufungsvision ursprünglich zusammengehören. - Eine eingehende Analyse von 1,1 - 3,15 ist in diesem Zusammenhang nicht möglich. 
aus nichts miteinander $z u$ tun haben: der zweite die Berufung des Ezechiel zum Propheten an sein Volk in Jahweworten und in der "Buchrollenvision", der erste die Schau letztlich des $k^{e}$ bòd jhwh $(1,28 a)$.

Der Berufungsbericht gehört an den Beginn der Wirksamkeit des Ezechiel, er stand zunächst auch zu Recht - mit der einleitenden Überschrift in 1,2.3a - am Anfang einer Sammlung von Ezechieltexten.

Daß die Thronwagenvision ursprünglich nicht mit dem Berufungsbericht verbunden war, macht schon der Sachverhalt wahrscheinlich, daß allein dieser Text eine relativ umfangreiche "Kommentierung" durch Zusätze erfahren hat ${ }^{148}$, nicht aber der Berufungsbericht. Für seine späte Entstehung - entsprechend 1,1 im 30. Jahr (der Verbannung Jojachins) - spricht, daß allein er mit der Überschrift in 1,1 "so offen den himmlischen Wohnsitz Jahwes voraussetzt" ${ }^{149}$. Überall sonst im Ezechielbuch ist die "Herrlichkeit Jahwes bzw. des Gottes Israel" im Zusammenhang mit dem Tempel bzw. der Stadt Jerusalem (10,4a.b.18; $11,23 ; 43,4.5 ; 44,4$ bzw. 8,$4 ; 9,3 ; 10,19 ; 11,22 ; 43,2)$ und einmal in einer Ebene bei Tel Abib (3,23), jedenfalls stets auf der Erde "geschaut"; nur die Thronwagenvision läßt den Propheten die Herrlichkeit Jahwes im Himmel, wie 1,1 ausdrücklich feststellt, sehen. Und der späten Entstehung dieser Vision entspricht es, daß die Bezugnahme auf sie im Ezechielbuch - zumeist erkennbar an den Stichwörtern ḩăjjôt "Lebewesen" (1,5 usw.) und/oder Jôpăn "Rad" (bzw. plur.; 1,15 usw.) ausnahmslos sekundär in den sie jetzt umgebenden Kontext

$148 \mathrm{Zu}$ diesen vgl. ZIMMERLI, Ezechiel Bd. 1, 1f. $23 \mathrm{ff}$. 149 ZIMMERLI, Ezechiel Bd. 1, 46. 
eingearbeitet sind: $3,12 \mathrm{~b} \cdot 13^{150} \cdot 23 \mathrm{a} \beta ; 10,8-17^{151}$ und in Verbindung damit "und er trat neben das Rad" in V.6b, "zwischen den Keruben" in V.7a; weiter 10,19aß.20-22; 11,22aß; 43,3aß.

Die Thronwagenvision in 1,1.3b.4-28a ist also wohl eine selbständige Größe. Sie stammt aus dem 30. Jahr der Verbannung Jojachins, d.h. aus dem Jahr 569/8, genauer vom 5. Juli 569. Geht man davon aus, daß Ezechiel bei seiner Deportation im März/April 597 etwa 5 Jahre Priester (vgl. 1,3) war und bei der Ubernahme des Priesteramtes ein Alter von 30 Jahren hatte (vgl. Num 4,3 usw.), dann war er bei dem Empfang dieser Vision ca. 65 Jahre alt, stand also am Ende seines Lebens. Zu dieser Zeit hat dann die großartige Vision, die ihn die "Herrlichkeit Jahwes" noch einmal, und nun in himmlischer Majestät, schauen ließ, seine Wirksamkeit als Prophet abgeschlossen.

Erst durch die Redaktion ist sie - fast wie ein Motto von der Herrlichkeit Jahwes - an den Anfang des Ezechielbuches gerückt und der Berufungserzählung vorangestellt worden. Dabei ist dann auch das Datum der Vision (mit der Einführung) der Einleitung des Buches (in V.2.3a) vor- und durch den "Synchronismus" (" $h \hat{\imath}^{2} "$ in V.2) ungeschickt und falsch gleichgesetzt worden.

150 Auch nach ZIMMERLI, Ezechiel Bd. 1, 33, ist V.13 Bestandteil einer Überarbeitung. V. 13b - "und Geräusch eines großen Erdbebens" - ist nicht nur Wiederholung des gleichlautenden Textes von V.12ar (vgl. ZIMMERLI a.a.0.), sondern "Wiederaufnahme" (vgl. dazu KUHL, Die "Wiederaufnahme"), und daraus ergibt sich, daß auch V.12 zum Einschub gehört - dies um so mehr, als das "Sicherheben" (zum Text s. die Kommentare) "der Herrlichkeit Jahwes von ihrem Ort" einerseits in dem Berufungsbericht überraschend kommt, da hier die Herrlichkeit Jahwes nicht genannt ist, andererseits aber die Herrlichkeit Jahwes, die sich ja nach der Thronwagenvision im Himmel befindet, nicht "hinter" dem Propheten (vgl. V.12aß), sondern nur "über" ihm sich von ihrem Platz erheben könnte.

151 V.13 kombiniert ausdrücklich den $g \breve{a} Z g \breve{a l}$ von V.2 mit den ôpănntm aus $1,15 \mathrm{ff.}$ - V.18 schließt an V.7 an. 
Exkurs: II Reg 25,27 par. Jer 52,31

Noch ein weiteres Ereignis ist im Alten Testament nach der Verbannung des Königs Jojachin datiert: die Begnadigung des Jojachin durch den Nachfolger des Nebukadnezar, den König AmelMarduk (hebr. Evil-Merodach) in II Reg 25,27 par. Jer 52,31. Die beiden Stellen sind hier mitzubehandeln. Sie berichten mit kleinen Varianten - folgendes:

Es geschah im 37. Jahr der Verbannung ( $z^{e}$ galut) Jojachins, des Königs von Juda, im 12. Monat am 27. 152 [Jer: 25. 153] (Tag) des Monats, da hob Amel-Marduk, der König von Babel, in dem Jahr seines Königsseins (måzkô [Jer: seiner Königsherrschaft: mălkutô]) das Angesicht Jojachins, des Königs von Juda, (Jer + und führte ihn heraus ${ }^{154}$ ) aus dem Hause der Haft ${ }^{155}$.

Die Wendung "das Angesicht heben" nimmt den Ritus auf, mit dem der Oberherr, etwa ein König, denjenigen, der in Proskynese vor ihm auf dem Boden liegt und - wie das Akkadische es ausdrückt - "die Nase (am Boden) streicht", aufnimmt, ihn also gnädig sich, dem König, zuwendet. Der Babylonier hat also den (ehemaligen) judäischen König begnadigt; die Fortsetzung des Textes bestätigt das.

Das Datum dieses Aktes ist mit Jahr, Monat und Tag ${ }^{156}$ angegeben. Die Datierung nach der Gefangenschaft (galût) des Jojachin setzt doch wohl dieselbe "Ära" voraus wie in Ez 1,1 (vgl. "unsere galutt"Ez 33,21; 40,1), Ausgangsjahr ist also hier wie

152 Die Datierung 28. in einer Handschrift (s. BHS) beruht auf einem Schreibfehler.

153 LXX: "24.". Grund oder Ursache dieser Änderung ist nicht zu sehen.

154 Die prägnante kürzere Form in II Reg 25,27 ist als lectio difficilior wohl die ursprüngliche.

155 II Reg:kälä). (LXX ${ }^{B A}:+$ seiner); Jer: $h a ̆ k k^{e} \imath \hat{\imath} / \hat{u}^{2}$ (wie in Jer 37,4): K hăkk $2 \hat{\imath}$, Q hăkke $\hat{u}^{2}$.

156 Die Differenz zwischen II Reg (27.) und Jer (25.) kann unberücksichtigt bleiben. 
dort das Jahr 598/7 157 ; die Begnadigung des Jojachin fand also im Jahr 562/1 statt.

Nun stellen beide Texte - in II Reg 25,27 und Jer 52,31 - für dieses Datum ausdrücklich einen Synchronismus her mit der Regierung des neubabylonischen Herrschers Amel-Marduk. Dieser König, Sohn und Nachfolger Nebukadnezars II., regierte von $562 / 1$ bis 560/59, genauer - soweit datierte Texte belegen vom 26. VI. des (im Frühjahr beginnenden) Jahres 562/1, nach dem julianischen Kalender vom 8. Oktober 562 , an bis in den 5. Monat des Jahres 560/59: er starb zwischen dem 7. und dem 13. Aug. $560^{158}$. Die Jahre $561 / 0$ und $560 / 59$ zählten als seine Regierungsjahre 1 und 2; die Zeit von seinem Regierungsantritt bis zum Ende des Jahres 562/1 galt als "am Anfang seiner Regierung", also als Akzessionszeit ${ }^{159}$. Die genaue Datierung nach II Reg 25,27 auf den 27. (bzw. nach Jer 52,31 auf den 25.) XII. weist in eben diese Akzessionszeit und führt nach unserer Zeitrechnung auf den 2. April (bzw. 31. März) 561 160 . Amel-Marduk hat also den Judäer begnadigt, als er knapp ein halbes Jahr regiert hatte. Es dürfte demnach eine Amnestie im Zusammenhang mit der Regierungsübernahme durch den Babylonier vorliegen.

Für die Akzessionszeit des Babyloniers wäre im hebräischen Text

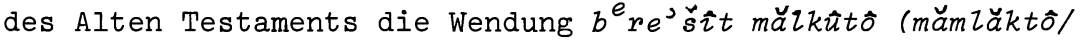
măm $e^{e}$ kutto $)$ zu erwarten, wie sie in Jer 26,$1 ; 27,1 ; 28,1$; 49,34 vorliegt. Aber die Angaben lauten hier anders; wir stellen den Wortlaut der Wendung nach MT und LXX zusammen:

$$
\begin{aligned}
& \text { II Reg 25,27: bišsenăt mårkô }
\end{aligned}
$$

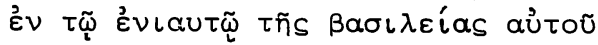

$$
\begin{aligned}
& \text { Jer 52,31: biše năt mălkutô }
\end{aligned}
$$

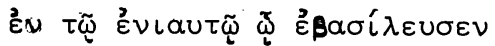

157 S. dazu oben $\$ 0$.

158 PARKER-DUBBERSTEIN, Babylonian Chronology, 12; SACK, AmelMarduk, Nr. 42 (frühester) bzw. Nr. 85 (spätester Text). Vgl. auch. RLA I, 94.

159 In diese Zeit gehören die Texte BACK, Amel-Marduk, Nr. 62, $25,54,43,44,20 ; 55,59$.

160 Vgl. PARKER-DUBBERSTEIN, Babylonian Chronology, 28. 
Die hebräischen Angaben sind durchaus ungewöhnlich und in dieser Form im Alten Testament ohne Parallele. Wo sonst in einer Zeitangabe biš $n a ̆ t$ und målkố oder mălkûut verbunden sind, wird immer die Jahreszahl angegeben: bišs năt šalôš $\tau^{e}$ malkô Est 1,3 (weitere Belege mit $\tau^{e}$ måkkô: Dan 9,2; II Chr 16,13) und

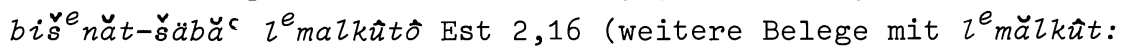
Dan 1,1; 8,1; I Chr 26,31; II Chr 3,2; 16,1.12). In II Reg 25,27 wie in Jer 52,31 fehlt eine solche Zahl - im hebräischen Text wie auch in den alten Übersetzungen. Die Angaben "im Jahre seines Königseins" (II Reg 25,27) bzw. "im Jahre seiner Königsherrschaft" (Jer 52,31) erwecken den Eindruck, als ob AmelMarduk nur ein Jahr regiert habe. Das aber widerspricht dem historischen Sachverhalt. Immerhin könnte man $\imath^{e}$ måk $\hat{o}$ in II Reg 25,27 im Sinne von "seines Königwerdens" und die ganze Angabe als "im Jahr seiner Thronbesteigung" verstehen ${ }^{161}$, weil das Verbum maZăk sowohl "König sein, als König herrschen", als auch "König werden" bedeuten kann; z.B. II Reg 16,1-2a: "(1) Im 17. Jahr des Pekach, des Sohnes des Remaljahu, malăk 'wurde König' Ahas, der Sohn Jothams, des Königs von Juda. (2a) 20 Jahre alt war Ahas $b^{e}$ malkô 'als er König wurde', und $16 \mathrm{Jah}-$ re malăk 'herrschte er als König' in Jerusalem." In II Reg

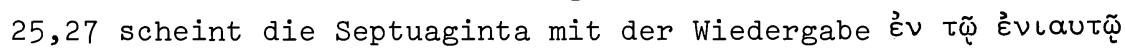

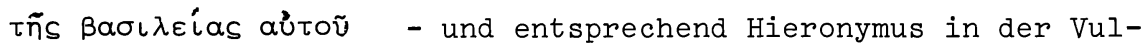
gata: anni regni - bei målkô eher an das Königsein als an das Königwerden gedacht zu haben ${ }^{162}$. Umgekehrt könnte die Wieder-

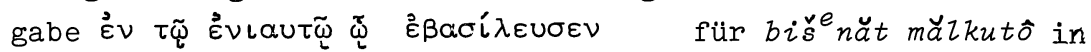
Jer 52,31 darauf hindeuten, daß der griechische übersetzer in der hebräischen Wendung das inkohative Moment des Königwerdens

161 So bereits Hieronymus: anno quo regnare coeperat; dann $\mathrm{z} . \mathrm{B}$. KITTEL, Die Bücher der Könige, 311; Jerusalem-Bibel, 495.

162 Das wird dadurch bestätigt, daß auch in den 11 weiteren Be-

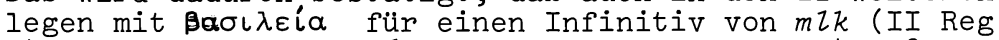
24,12; 25,1; II Chr 16,13; 17,7;21,5;29,3; 34,3.8; Jer 51 (LXX 28), 59; 52,4; Dan 9,2 [hier auch Theodotion]) das Verbum nie in inkohativer Bedeutung ("König werden") steht. 
gefunden hat ${ }^{163}$. So ist - nach dem uns yorliegenden Material vom hebräischen Sprachgebrauch her die Bedeutung "König werden" zwar für mălkût in Jer 52,31 ausgeschlossen ${ }^{164}$, für malăk in II Reg 25,27 aber wenn auch nicht sicher, so doch möglich. Darüber hinaus läßt die griechische Übersetzung gerade der Jeremia-Stelle erkennen, daß man die hier diskutierte Datierung schon in alter Zeit auf den Regierungsanfang des Amel-Marduk gedeutet hat. So ist auch yon der Textüberlieferung her zumindest die Möglichkeit gegeben, die Datierung in II Reg 25,27 und Jer 52,31 auf die Akzessionszeit des Amel-Marduk, also auf den dem Tod des Nebukadnezar II. folgenden Rest des Jahres. 562/1 zu beziehen.

Allerdings hat man in den beiden Wendungen auch das erste Regierungsjahr des Amel-Marduk, das Jahr 561/0, finden wollen. Auf dieses Jahr kommen vor allem jene Forscher, die die Gefangenschaft des Jojachin mit dem Jahr 597/6 (statt 598/7) beginnen lassen ${ }^{165}$. Indes ist dieser Annahme der alttestamentliche Text erst recht nicht günstig. In diesem Fall müßte die Zeitangabe bšnt 'ht $2 m \imath k w$ in II Reg 25,27 bzw. b̌̌nt 'ht $\imath_{m} l k t w$ in Jer 52,31 "im Jahr 1 seines Königseins (bzw. seines Königtums)" lauten (vgl. z.B. Dan 9,2); aber in der Textüberlieferung findet sich für beide Stellen keine Zahl für ein Regierungsjahr. Darüber hinaus aber ist die Frage des Jahres, in dem Amel-Marduk den Jojachin begnadigt hat, bereits dort entschieden, wo als Jahr der Beginn der Gefangenschaft des Judäers

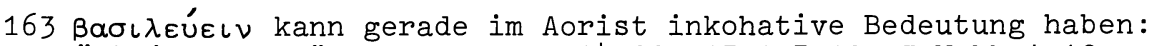
"König werden"; vgl. II Reg 14,29; 15,1.7.10; I Makk 1,10 u.ö.; Apk 11,17. Hierzu sowie zu außerbiblischen Belegen s. die Lexika.

164 Trotzdem ist auch Jer 52,31 immer wieder auf den Regierungsantritt des Babyloniers hin verstanden worden; so etwa von VOLZ, Jeremia, 374.377; RUDOLPH, Jeremia, 322.325; WEISER, Jeremia. Kap.25,15 - 52,34, 451.454; BRIGHT, Jeremiah, 366, Jerusalem-Bibel, 1171.

165 Etwa VOGT (s. oben $37 \mathrm{ff.}$ ) und MALAMAT (s. oben 15f.); weiter etwa JEPSEN, Chronologie, 23; ANDERSEN, Chronologie, 110. - Die Datierung der Begnadigung des Jojachin "um das Jahr 560 v. Chr." (so S. HERRMANN, Geschichte Israels, 354) übergeht das Problem mit einer vagen Angabe. 
$598 / 7$ (und nicht 597/6) festzustellen war ${ }^{166}$. Von 598/7 aus ist bei altorientalischer Zählweise das 37. Jahr das Jahr 562/1 (und nicht 561/0).

Die Notwendigkeit, die Angabe über das Regierungsjahr des AmelMarduk in II Reg 25,27 und Jer 52,31 auf seine Akzessionszeit zu deuten ${ }^{167}$, ist also nicht von der sprachlichen Formulierung der Texte her, sondern von chronologischen Erwägungen aus gegeben.

4. $\operatorname{Ez} 8,1$

Wie das Datum in Ez 1,2 setzen auch die übrigen Zeitangaben des Ezechielbuches - außer derjenigen in 24,1 - die "Ära" der Verbannung mit 598/7 als Jahr 1 voraus, ohne daß dies dort ausdrücklich gesagt ist, wie es in 1,2; 33,21 und 40,1 der Fall war. In der weiteren Darstellung gehen wir nun im wesentlichen der zeitlichen Reihenfolge der Daten nach. Dieser entspricht auch die Mehrzahl der Belege; nur 29,17 rückt an das Ende.

In 8,1 wird - wie in 40,1 und 1,1 - eine Vision zeitlich fixiert, und zwar auf den 5. VI. 6. Während die Ältesten Judas bei ihm in seinem Haus sitzen, wird Ezechiel "in Gottesgesichten" (V.4) nach Jerusalem entrückt, um dort "die große Schau vom sündigen Gottesdienst Jerusalems und seinem Gericht"168 $\mathrm{zu}$ erfahren $\left(8,4^{\prime}-11,23\right)$; über diese berichtet er nach seiner "Rückkehr" $(11,24)$ den Ältesten $(11,25)$.

In der Textüberlieferung und in ihrem Gefolge in der wissenschaftlichen Diskussion ist die Monatsangabe umstritten: LXX hat statt dem 6. Monat des MT den 5. Monat. Da aber die zugunsten des 5. Monats angestellten Berechnungen ${ }^{169}$ ungenau sind, fehlt für eine sekundäre Änderung des (angenommen ursprüng-

$166 \mathrm{~S}$. oben 40.

$167 \mathrm{Vgl}$. dazu BEGRICH, Chronologie, 61 Anm.1.

168 So ZIMMERLI.

169 S. nach anderen etwa FOHRER, Hauptprobleme, 116. 
lichen) 5. Monats in den 6. Monat die Begründung ${ }^{170}$. So wird man bei dem MT bleiben ${ }^{171}$. Der 5. VI. des von $598 / 7$ aus gezählten Jahres 6 ist - entgegen der üblichen Ansetzung in das Jahr $592 / 1^{172}-$ der 28. Sept. $593^{173}$.

5. Ez 20,1

Das in Ez 20,1 genannte Datum des 10. V. 7 fixiert die Begebenheit, daß einige der "Ältesten Israels" den Propheten aufsuchen, um Jahwe zu befragen. Ein Jahwewort an Ezechiel lehnt eine Befragung $a b(V .31 b)$ und begründet dies mit der Widerspenstigkeit, die die Israeliten seit seiner Selbstoffenbarung in Ägypten gegenüber Jahwe geübt haben (V.2 - 31a). Das Ereignis fällt auf den 24. Aug. 592.

Über den Inhalt der Anfrage sagt der Text nichts. Daß die Exulanten einen eigenen Opferdienst in Babylonien, in welcher Form auch immer, wünschten ${ }^{174}$, setzt voraus, daß V. 32 (nicht zu der nachfolgenden Heilsankündigung, sondern) zu dem ablehnenden Jahwewort gehörte; indes liegt der Einschnitt vor V. $32^{175}$. Auch die Annahme, die Anfrage suche eine Bestätigung dafür, daß mit Hilfe der Ägypter Nebukadnezar besiegt und die Exulanten die Rückkehr in die Heimat gewinnen würden ${ }^{176}$, bleibt in ihrem ersten Teil Spekulation, da der Text selbst

170 Die genauen Berechnungen bei ZIMMERLI, Ezechiel Bd. 1, $190 f$.

171 Mit ZIMMERLI, Ezechiel Bd. 1, 191.

172 ZIMMERLI, Ezechiel Bd. 1, $15^{+}: 17$. Sept. 592.

173 Die Jahreszahl (593/2) auch bei FOHRER, Ezechiel, 48. Doch bleibt diese Ansetzung des Jahres 6 unbegründet und wird nicht mit der Ansetzung des Jahres 7 in das Jahr 591/0 (a.a.0. 108) ausgeglichen. - Die Umrechnungen hier und im folgenden wiederum nach PARKER-DUBBERSTEIN, Babylonian Chronology, 28.

$174 \mathrm{Vgl}$. etwa ROTHSTEIN, Jeremia, 919; BEWER, Beiträge zur Exegese des Buches Ezechiel, 195ff.; FOHRER, Ezechiel, 108.

175 S. ZIMMERLI, Ezechiel Bd. 1, 438.

176 FREEDY-REDFORD, The Dates in Ezekiel, 470. 
nicht in diese Richtung weist ${ }^{177}$. Eher ist - so der zweite Teil - an den Wunsch nach Aufhebung der Verbannung und Rückkehr in die Heimat zu denken ${ }^{178}$.

6. Ez 24,1

Das Datum von Ez 24,1 nimmt gegenüber allen anderen Zeitangaben im Ezechielbuch eine Sonderstellung ein. Der Text von V.1-3a lautet: "(1) Und es erging das Wort Jahwes an mich im 9. Jahr, im 10. Monat, am 10. (Tag) des Monats: (2) Menschensohn, schreibe dir den 'Namen' (d.h. das Datum) des Tages, eben diesen Tag auf. Der König von Babel hat sich an eben diesem Tag auf Jerusalem geworfen. (3) Und sage ein Gleichniswort zu dem Hause Widerspenstigkeit und sprich zu ihnen: So hat der Allherr Jahwe gesprochen: ..."179 . Es folgt in V.3b-5 der Auftrag an den Propheten zu einer Gleichnishandlung mit einem Kessel, aus der dann in V.6-14 eine - mehrschichtige 180 - Unheilsankündigung entwickelt wird.

Das hier genannte Datum ist nach II Reg 25,1 ( $\operatorname{Jer} 52,4$; vgl. 39,1) der Tag, an dem die Belagerung Jerusalems durch Nebukadnezar begonnen hat. Nach Ez 24,1 hat der Prophet das Ereignis am Tage seines Eintretens erfahren. Dieser Sachverhalt hat den Auslegern Schwierigkeiten bereitet und sie zu mancherlei Erklärungen angeregt ${ }^{181}$. Der Lösung des Problems dient es, wenn man das Datum in zweifacher Hinsicht näher betrachtet ${ }^{182}$.

177 Das gilt auch dann, wenn der Zug des Pharao Psammetich II. nach Palästina in seinem 4. Jahr - der nach FREEDY-REDFORD, The Dates in Ezekiel, 470 den Hintergrund des Jahwewortes in Ez 20,2-31 bildet - in das Jahr 592/1 gehört; so MALAMAT, The Twilight of Juda, 141.

178 So bereits ZIMMERLI, Ezechiel Bd. 1, 441 mit dem Hinweis auf $\mathrm{Ez} 36,37$.

179 Zum Text vgl. ZIMMERLI, Ezechiel Bd. 1, 556.

$180 \mathrm{Vgl}$. dazu ZIMMERLI, Ezechiel Bd. 1, $560 f$.

$181 \mathrm{Vgl}$. die kritische Aufstellung bei FOHRER, Hauptprobleme, $116 \mathrm{ff}$., auch ZIMMERLI, Ezechiel Bd. 1, $562 \mathrm{f}$.

182 Zum Folgenden vgl. ZIMMERLI, Ezechiel Bd. 1, 562. 
1. Zur Form der Datierung: Die Angabe des Monats unterscheidet sich von allen entsprechenden Notierungen im Ezechielbuch. Sonst wird die (bis zur Zahl 10 übliche) Ordinalzahl einfach mit $b$ eingeführt; z.B. ba $a^{c a s ́ s} \hat{\imath}$ "im 10. (Monat)" 29,1; 33,21. Demgegenüber ist in 24,1 die Bezeichnung "Monat" miteingeführt: băhodäš ha ${ }^{c a} s \hat{\imath} r \hat{\imath}$ "im 10. Monat". Diese Form der Monatsangabe stimmt - bei wörtlicher Entsprechung auch der Angabe von Jahr und Tag - genau überein mit der Datierung des Belagerungsbeginns in II Reg 25,1 (= Jer 52,4; in Jer 39,1 ohne Tagesangabe).

2. Zur Stellung des Datums im Satz: Bei den übrigen Daten des Ezechielbuches, die mit der Wortereignisformel verbunden sind, folgt das Datum stets auf das einleitende wjhj $(1,1 ; 8,1 ; 20,1$; $33,21)$, das in 26,1; 29,17; 30,20; 31,1; $32,1.17$ nach der Datumsangabe durch $h j h$ aufgenommen wird ${ }^{183}$. Hier in 24,1 steht das Datum ungewöhnlicherweise erst nach der Wortereignisformel.

Die Übereinstimmung in der Form der Datumsangabe von 24,1 macht die Nähe zu der Datierung in II Reg 25,1 deutlich. Die Abweichung von der sonst im Ezechielbuch üblichen Wortstellung zeigt, daß die Datumsangabe in 24,1 gegenüber II Reg 25,1 nicht primär ${ }^{184}$, sondern sekundär ist ${ }^{185}$. Zu fragen ist nur, ob in Ez 24,1 ursprünglich überhaupt kein Datum gestanden hat oder ein anderes, das durch das jetzige aus II Reg 25,1 ersetzt worden ist. In beiden Fällen wären der Auftrag, das Datum dieses Tages festzuhalten, und der Hinweis auf das Ereignis dieses Tages, den Beginn der Belagerung von Jerusalem, sekundär, da sie mit dem jetzigen Datum zusammenhängen. Allerdings ist die nachträgliche Änderung eines Datums, um ein nachfolgendes Jahwewort sekundär auf ein bestimmtes Ereignis zu beziehen, weniger wahrscheinlich. Ohne das Datum muß der ursprüngliche Text begonnen haben: "Und es erging an mich das Wort Jahwes folgen-

183 In 29,1 ist das einleitende wjhj weggefallen.

184 So FOHRER, Hauptprobleme, $118 \mathrm{f}$.

185 So ZIMMERLI, Ezechiel Bd. 1, 562. 
dermaßen: Menschensohn, sage ein Gleichniswort ..."; vgl. 3,16; 6,1; 7,1 usw. (zumeist mit der Anrede "Menschensohn").

Die Erkenntnis, daß das Datum in 24,1 aller Wahrscheinlichkeit nach nicht von Ezechiel, sondern aus II Reg 25,1 stammt, bedeutet, daß in Ez 24,1 wie in II Reg 25,1 mit dem "9. Jahr" das 9. Regierungsjahr des Königs Zedekia gemeint ist. Für ZIMMERLI ergibt sich dann keine Änderung des absoluten Datums (in unserer Zeitrechnung), da für ihn das 9. Jahr des Zedekia dem 9. Jahr der Verbannung entspricht. Für die vorliegende Untersuchung dagegen ist diese Erkenntnis von besonderer Wichtigkeit. Wäre das hinsichtlich seiner "Ära" nicht näher bestimmte Jahr 9 von Ez 24,1 auf die Verbannung des Jojachin zu beziehen, wäre damit das Jahr 590/89 gemeint - womit aber der in V.2 anvisierte Beginn der Belagerung um 1 Jahr zu früh angesetzt wäre. Dieses Problem entfällt, da das in 24,1 genannte Jahr wie in II Reg 25,1 das 9. Jahr des Zedekia ist. - Der 10. X. des 9. Jahres des Zedekia ist der 15. Jan. $588^{186}$.

7. $\quad$ Ez 26,1

Die restlichen Daten legen den Zeitpunkt der Entstehung von Sprüchen gegen Fremdvölker fest. Die Völkerorakel in Ez 25-32, die den genannten Völkern Unheil ankündigen, verteilen sich auf zwei Gruppen: 25,1 - 28,23 und 29,1 - 32,32. Die erste Gruppe enthält Sprüche gegen die Ammoniter (25,1-7), gegen Moab (25,811) und Edom $(25,12-14)$, gegen die Philister (25,15-17) und gegen Tyrus (26,1-21; dazu 27,1-36 und zwei Sprüche gegen den König von Tyrus 28,1-10 und 11-19) 187.188 . Als Schuld, die Jahwes Gerichtshandeln hervorgerufen hat, wird für die Ammoniter, für Moab und Tyrus ${ }^{189}$ festgestellt, daß sie über den

186 So auch ZIMMERLI, Ezechiel Bd. 1, $15^{+}$.

$187 \mathrm{Zu}$ den Tyrussprüchen vgl. ZIMMERLI, Ezechiel Bd. 2, 601. $622 f .662$.

188 Das Wort gegen Sidon in 28,20-23 stammt "aus der Hand des Mannes, der Ez 25-28 zusammengefaßt ... hat"; ZIMMERLI, Ezechiel Bd. 2, 693.

189 So in dem Grundbestand 26,1-5a des ersten Tyruswortes; vgl. ZIMMERLI, Ezechiel Bd. 2, $622 f$. 
Untergang von Juda triumphiert haben $(25,3 \mathrm{~b} .6 .8 ; 26,2)$, für Edom und die Philister, daß sie (in dem sie sich an judäischem Gebiet bereichert haben) "aktive Rachetat"190 an Juda geübt haben. Diese Worte setzen also den Untergang von Juda und Jerusalem im Sommer 587 voraus.

Von diesen Sprüchen ist allein das erste Wort gegen Tyrus in 26,1(-6) datiert, und zwar auf den 1. Tag eines nicht genannten Monats "im 11. Jahr". Berücksichtigt man, daß Ezechiel ein solches Wort erst nach dem Eingang der Nachricht vom Fall der Stadt Jerusalem - d.h. nach dem 5. X. des Jahres 587/6 gesprochen haben kann, kommen als Monat nur der 11 . oder der 12. in Betracht ${ }^{191}$. Wie aber ist die Angabe des "11. Jahres" $\mathrm{zu}$ verstehen? Wer die Jahre der Verbannung den Regierungsjahren des Zedekia gleichstellt, kann an das 11. Jahr dieses Königs (d.h. 587/6) denken. Nur: Die "Jahre" etwa des Jojachin nach seiner Absetzung werden nach seiner Verbannung, nicht als "Jahr $\mathrm{x}$ des Jojachin" gezählt. Bereits von hieraus ist die Zahl 11 verdächtig ${ }^{192}$. Ist aber das Jahr von 26,1 - wie auch die Ausleger sonst annehmen - nach der Verbannung gezählt, dann ist für das Jahr $587 / 6$ hier wie in $33,21^{193}$ das 12 . Jahr zu erwarten - und sicher ursprünglich. Dieses, das 12. Jahr, bietet zwar LXX ${ }^{A}$. Aber darauf kann man sich nicht berufen ${ }^{194}$. Denn LXX ${ }^{A}$ nennt außerdem - über MT hinaus - einen Monat, und zwar den ersten. Die Handschrift hat also mit dem 1. I. 12 das Datum des Spruchs um zwei Monate bzw. um einen Monat (gegenüber dem oben erwogenen "11." bzw. "12. Monat" des Jahres 11) hinausgeschoben. Aber eine andere textkritische Beobachtung stützt die Annahme, daß in 26,1 ursprünglich das "12. Jahr"

190 ZIMMERLI, Ezechiel Bd. 2, 599.

191 ALBRIGHT, The Seal of Eliakim, 93; FOHRER, Ezechiel, 149; EICHRODT, Hesekiel Kap. 19-48, 246.249; ZIMMERLI, Ezechiel Bd. 2, 613.

192 Auch daß man zur Erklärung der Zahl 11 auf die Zitierweise von II Reg 25 usw. zurückgreift (s. oben 62f.zu 24,1), ist nicht möglich.

193 S. dazu oben $41 \mathrm{ff}$.

194 Gegen FOHRER, Ezechiel, 149; LANG, Ezechiel, 36. - Die Versionen bieten im übrigen das 11. Jahr. 
gestanden hat. Das Ezechielbuch gebraucht für das Jahr 11 sonst

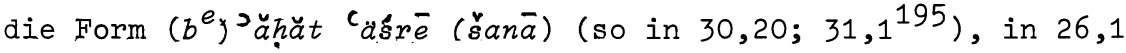

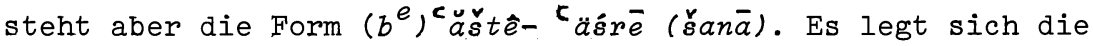
Annahme nahe, daß diese für das Ezechielbuch ungewöhnliche Bezeichnung für das 11. Jahr durch Einfügung des ${ }^{C}$ aus bišté ("srh šnh) "im 12. Jahr" verschrieben ist. Diese Annahme wird dadurch gestützt, daß dieselbe Verschreibung der Zahl štj csish (12) in čstj csph (11) im Ezechielbuch noch einmal, nämlich in 40,49 yorkommt, wo die Zahl "11" Ellen (so MT) unmöglich ist"196 So ist auch von dieser Seite her die Zahl "12" für das in 26,1 genannte Jahr wahrscheinlich zu machen. Hier ist also der 1. XI oder 1. XII. 587/6 (= 13. Febr. oder 15. März 586) gemeint.

8. Ez 29,1;30,20; 31,1;32,1.17

Die zweite Gruppe der Völkerorakel, 29,1 - 32,32, enthält nur Worte gegen Ägypten bzw. den Pharao. Während in der ersten Gruppe in Ez. 25,1 - 28,23 nur ein Spruch, der erste gegen Tyrus, ein Datum aufweist, sind hier in der zweiten Gruppe sechs Worte datiert:

$$
\begin{aligned}
& \text { 29,1: 12. X. } 10 \\
& \text { 29,17: 1. I. } 27 \\
& \text { 30,20: 7. I. } 11 \\
& \text { 31,1: 1. III. } 11 \\
& \text { 32,1: 1. XII. } 12 \\
& \text { 32,17: 15. ? } 12 .
\end{aligned}
$$

Diese Daten liegen zum Teil deutlich in einer Reihenfolge: 12. X. $10(29,1)$ bis 1 . XII. $12(32,1)$. Aus dieser Reihe fällt nur der 1. I. 27 in 29,17 heraus. Der Spruch 29,17-20 gehört inhaltlich in eine spätere Zeit, die Jahreszahl 27 ist also nicht anzuzweifeln. Vielleicht hat er einmal am Ende der Sammlung von Agyptenworten gestanden; die (dann an die ganze Samm-

195 Ein 11. Tag oder 11. Monat ist im Ezechielbuch nicht genannt.

196 ZIMMERLI, Ezechiel Bd. 2, 990. 
lung anschließende) Heilsankündigung für das "Haus Israel" in 29,21 könnte ein Indiz dafür sein ${ }^{197}$.

Keine Schwierigkeiten bereiten die Daten 12. X. $10=17$. Jan. 588 in 29,1, 7. I. $11=10$. April 588 in 30,20 und 1. III. $11=$ 2. Juni 588 in 31,1. Ez. 29,1ff. bietet "das älteste datierte Fremdvölkerwort"198. Wenn die Belagerung Jerusalems am 10. X. 9 Zedekia $=10 . X .10$ der Verbannung ${ }^{199}$ begonnen hat, dann hat Ezechiel zwei Tage später, am 12. X. 10 der Verbannung, noch keine Kenntnis davon gehabt; wohl kann er zu diesem Zeitpunkt von dem Marsch Nebukadnezars nach Palästina gewußt haben. Daß diese Unternehmung des Babyloniers auch Ägypten bedrohe, kann der Prophet durchaus angenommen haben. Entsprechendes wird man für das Datum des 7. I. 11 in 30,20 kalkulieren 200 . Erst am 1. III. $11(31,1)$ könnte der Beginn der Belagerung bei den Exulanten bekannt gewesen sein; ob auch das Scheitern eines ägyptischen Entlastungsangriffes (vgl. Jer 37,5) zu diesem Zeitpunkt dort schon gemeldet war, ist mehr als zweifelhaft. Daß Ägypten den Aufstand Judas und anderer Völker gegen die Babylonier schürte, hat man auch ohne diese Nachrichten gewußt. Gegenüber diesen Daten ist die zeitliche Fixierung des nächsten datierten Ägyptenwortes auf den 1. XII. 12 in 32,1 wiederholt angezweifelt worden. Die Ansetzung des Jahres 1 der Verbannung auf 597/6 ließ das Datum des 1. XII. 12 (=3. März 585) zu spät erscheinen. Deshalb hat man immer wieder - unter Berufung auf die Lesart von 13 hebräischen Handschriften, LXX ${ }^{A}$ und Syrer -

$197 \mathrm{Vgl}$. das Heilswort in 28,24-26 am Ende der ersten Sammlung von Völkersprüchen.

198 ZIMMERLI, Ezechiel Bd. 2, 706.

199 S. oben 63.

$200 \mathrm{Vgl}$. das oben $45 \mathrm{zu}$ der Dauer der Reise des Esra Gesagte. 
das 11. Jahr hergestellt 201 . Aber - abgesehen von der schlechten textkritischen Bezeugung - eine solche Anderung der Jahresangabe von 32,1 erübrigt sich (ebenso wie diejenige von $33,21^{202}$ ), wenn man - wie es hier geschieht - die Jahre der Verbannung von $598 / 7=$ Jahr 1 rechnet. Dann ist der 1 . XII. 12 = 15. März 586 das Datum, das man mit der Änderung in das Jahr "11" erreichen wollte.

Hat sich so das Datum des 1. XII. 12 als zuverlässig erwiesen, ist auch das Problem der Zeitangabe von 32,17 zu klären. Wenn hier, ebenfalls für das Jahr 12, der 15. eines nicht genannten bzw. nicht erhaltenen Monats aufscheint, kommt - die Richtigkeit beider Zahlen vorausgesetzt - nur der 15. XII. 12 in Frage: Das ist der 29. März 586.

So liegen die datierten Ägyptensprüche - abgesehen von 29,1720 - teils vor dem Beginn der Belagerung von Jerusalem (29,1; $30,20)$ bzw. bald nach deren Bekanntwerden bei den Exilierten $(31,1)$, teils nach dem Eingang der Nachricht von der Eroberung der Stadt $(32,1 ; 32,17)$. Ein Bezug zu einem konkreten Ereignis, etwa einem Angriff Nebukadnezars auf Ägypten, in dieser Zeit ist nicht erkennbar.

\section{9. $\operatorname{Ez~29,17}$}

In sehr viel späterer Zeit hat Ezechiel noch einmal ein Jahwewort gegen Ägypten gesprochen: am 1. I. 27, das ist - nach der hier kalkulierten Zählung der Verbannungsjahre - der 8. April 572. Es ist das letzterhaltene Wort des Propheten, nur die große Thronwagenvision in 1,1.3b.4-28a liegt noch drei Jahre

201 So etwa J. HERRMANN, Ezechiel, 193; BERTHOLET, Hesekiel (HAT), 110f.; FOHRER, Ezechiel, 177; EICHRODT, Hesekiel. Kap. 19-48, 296; FREEDY-REDFORD, The Dates of Ezekiel, 468 Anm. 30; BHK und - etwas vorsichtiger - ZIMMERLI, Ezechiel Bd. 2, 762f.767; BHS. Dagegen etwa COOKE, Ezekiel, 346; schwankend LANG, Ezechiel, 38 (er setzt - wie VOGT Jahre der Verbannung um 1 Jahr höher an als die Regierungsjahre des Zedekia, s. oben 20 Anm. 28).

202 S. dazu oben $41 f f$. 
später ${ }^{203}$. Wie schon früher $(30,10.24 f . ; 32,11)$ kündigt Ezechiel auch in 29,18-20 Agypten an, daß der Babylonier das Unheil über das Land bringen wird (V.19f.). Neu ist, daß die Gabe des Landes Ägypten an Nebukadnezar verstanden ist als eine Art von Entgelt für vergebliche Mühe, die er im Kampf gegen Tyrus aufgewandt hat. Über die geschichtliche Situation, die hier vorausgesetzt ist, gibt uns Josephus Auskunft (c.Ap. I, 156-159; ant. X, 228): Nebukadnezar hat Tyrus unter dem König Ithobaal 13 Jahre lang belagert.

Wie hat dieses langwierige Unternehmen geendet? Ein babylonisches Tonprisma mit einem "Hofkalender" etwa aus dem Jahre 570 führt in einer Liste von phönizischen Vasallen an erster Stelle Tyrus auf; und eine Urkunde, in Tyrus geschrieben, aus dem 41. Jahr des Nebukadnezar $(=564 / 3)$ nennt einen babylonischen Oberkommissar in der stadt ${ }^{204}$. Nebukadnezar hat also die stadt in die Hand bekommen; aber er hat sie nicht erobert, im Sturm genommen - das hat erst Alexander der Große im Jahr 332 mit Hilfe eines von der Küste zur Insel aufgeschütteten Dammes erreicht. Wie schon mehrfach in der vorangegangenen Geschichte wurde die Inselstadt durch Mangel an "Brot und Wasser" zur Kapitulation gezwungen ${ }^{205}$. Offenbar ist es aber nicht zu einer Plünderung der Stadt durch das babylonische Heer gekommen. Diese Situation setzt der Spruch Ez 29,17-20 voraus: Der "Lohn", den Nebukadnezars Soldaten in Tyrus nicht gewonnen haben, soll ihnen in Ägypten zuteil werden.

Ez 29,17 gibt also mit dem 1.`I. $27=8$. April 572 den Terminus ante quem für das Ende der 13jährigen Belagerung. Auf der anderen Seite setzt das auf den 1.XI./XII. des 12. Jahres der Verbannung $=13$. Februar/ 15. März $586^{206}$ datierte Wort in Ez 26,1-6 eine unmittelbare Bedrohung von Tyrus noch nicht

203 S. oben $53 f$.

204 Vgl. dazu UNGER, Nebukadnezar II. ... in Tyrus. $205 \mathrm{Vgl}$. das Material bei ZIMMERLI, Ezechiel Bd. 2,602f. 206 S. dazu oben $64 f$. 
voraus. Zwischen diesen beiden Daten liegen die 13 Jahre der Belagerung von Tyrus. Dabei wird man auch hier mehrere Monate für den Weg der Nachricht von der Kapitulation der stadt nach Babylonien einkalkulieren müssen. Zumeist hat man in neuerer Zeit die Belagerung in die Jahre 585 bis 572 angesetzt 207. Entsprechend dem Berechnungsmodus, den wir für die Belagerung yon Samaria ermittelt haben - drei Jahre Belagerung $=4$. bis 6 . Jahr Hiskia $=724 / 3$ bis $722 / 1^{208}$, ist eher mit um $1 \mathrm{Jahr}$ verringerten Zahlen zu rechnen: $586 / 5$ bis $574 / 3$ oder $585 / 4$ bis $573 / 2^{209}$. Mehrfache Versuche, den Angaben, die Josephus in diesem Zusammenhang macht, weitere Aufschlüsse für die Ansetzung der 13 Jahre Belagerung von Tyrus zu entnehmen ${ }^{210}$, führen nicht zu genaueren Ergebnissen.

207 So FLEMING, The History of Tyre, 44 (585 = $1 \mathrm{Jahr}$ nach der Eroberung yon Jerusalem 586); danach UNGER, Nebukadnezar II. ... in Tyrus, 314; EISSFELDT, Das Datum der Belagerung von Tyrus, 421 bzw. 1.

208 S. dazu oben 39.

209 Die letztere Angabe auch schon bei COOKE, Ezekiel, 287. $210 \mathrm{Vgl}$. etwa KATZENSTEIN, The History of Tyre, $325 \mathrm{ff}$. 
III. Die Ergebnisse

Wir fassen die Ergebnisse zusammen.

1. Die erste Eroberung von Jerusalem erfolgte am 2. Adar

( = XII.) $598 / 7=16$. März 597, die zweite Eroberung (mit nachfolgender Zerstörung von Stadt und Tempel) nach II Reg 25,3f. = Jer 52,6f. (das Jahr des Nebukadnezar ist in II Reg 25,8 = Jer 52,12 um 1 Jahr zu hoch angesetzt: 19. statt richtig 18.) am 9. IV. $587 / 6=29$. Juli 587 .

2. Nach den alttestamentlichen und babylonischen Quellen wurde der judäische König Jojachin zwischen dem 2. Adar 598/7 und dem Ende dieses Monats von Nebukadnezar gefangengenommen und in die Verbannung nach Babylonien in Marsch gesetzt. In derselben Zeit, noch vor dem Beginn des Jahres 597/6 - 1. Nisan (= I.) 597 = 13. April 597 - wurde Zedekia durch den Babylonier zum König in Juda eingesetzt.

3. Berücksichtigt man den biblischen Sprachgebrauch, dann galt für die Judäer in Palästina wie in der Verbannung in Babylonien das Jahr, in dem der König Jojachin verschleppt wurde, das heißt das Jahr 598/7, als das erste Jahr der Verbannung. Von hier aus sind die Jahre in den Daten des Ezechielbuches (außer $24,1)$ sowie in II Reg 25,27 par. Jer 52,31 gezählt, entsprechend das 14. Jahr "nach der Einnahme der Stadt (Jerusalem)"

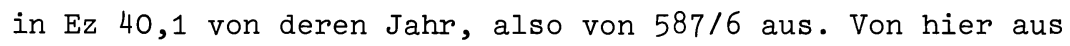
erübrigen sich zwei häufig geübte Konjekturen an Jahresangaben, nämlich in $\mathrm{Ez} 32,1$ und 33,21; lediglich für 26,1 ergibt sich eine schon früher mehrfach erwogene, graphisch naheliegende Änderung.

4. Nur das 9. Jahr von Ezechiel 24,1 ist nach den Regierungsjahren des Königs Zedekia (Jahr $1=597 / 6)$ gerechnet.

5. Auch das "30. Jahr" yon Ez 1,1 meint die Ära "Verbannung". Die Thronvision in 1,4-28a, die den Propheten die Herrlichkeit Jahwes im Himmel schauen läßt $(1,1 \mathrm{~b})$, und die Berufungserzählung in $1,28 b ; 2,1-3,11$ gehören von Hause aus nicht zusammen; die Vision mit der Einleitung in 1,1.3b ist erst sekundär 
der das Buch eröffnenden Berufungserzählung (Einleitung $1,2^{+}$. 3a) vorangestellt worden.

6. Für die hier behandelten Daten ergeben sich folgende Ansätze in unserer Zeitrechnung ante Christum natum (Neb.= Nebukadnezar):

\begin{tabular}{|c|c|c|c|}
\hline$z$ 1,1: & 5. IV. 30 & $=5$. Juni 569 & $(=36 \cdot \mathrm{Neb})$. \\
\hline 1,2: & 5. (IV.?) 5 & $=$ (13. Juli?) 594/3 & $(=11 \cdot \mathrm{Neb})$. \\
\hline 8,1: & 5. VI. 6 & $=28 \cdot$ Sept. 593 & $(=12 \cdot \mathrm{Neb})$. \\
\hline $20,1:$ & 10. V. 7 & $=24 \cdot$ Aug. 592 & $(=13 \cdot \mathrm{Neb})$. \\
\hline $24,1:$ & 10. X. 9 (Zedekia!) & $=15 \cdot \operatorname{Jan} \cdot 588$ & $(=16 \cdot \mathrm{Neb})$. \\
\hline $26,1:$ & 1. (XI. oder XII.) & $=\begin{array}{c}\text { (13. Febr } \\
\text { 15. März }) 586\end{array}$ & $(=18 \cdot \mathrm{Neb})$. \\
\hline $29,1:$ & 12. $x \cdot 10$ & $=17 \cdot \operatorname{Jan} \cdot 588$ & $(=16 \cdot \mathrm{Neb})$. \\
\hline 29,17: & 1. I. 27 & $=$ 8. April 572 & $(=33 \cdot \mathrm{Neb})$. \\
\hline $30,20:$ & 7. I. 11 & $=10 \cdot$ April 588 & $(=17 \cdot \mathrm{Neb})$. \\
\hline 31,1: & 1. III. 11 & $=2$. Juni 588 & $(=17 \cdot \mathrm{Neb})$. \\
\hline $32,1:$ & 1. XII. 12 & $=15$. März 586 & $(=18 \cdot \mathrm{Neb})$. \\
\hline $32,17:$ & 15. (XII.) 12 & $=$ (29. März) 586 & $(=18 \cdot \mathrm{Neb})$. \\
\hline $33,21:$ & 5. X. 12 & $=19 \cdot \operatorname{Jan} \cdot 586$ & $(=18 \cdot \mathrm{Neb})$. \\
\hline 40,1: & $\begin{array}{r}\text { 10. I. } 25=10 . \text { I. } \\
\text { der Erober }\end{array}$ & $t=10 \cdot$ April 574 & $(=31 \cdot \mathrm{Neb})$. \\
\hline
\end{tabular}


T a b e 11 e $\mathrm{I}$

Zeittafel nach Malamat

\begin{tabular}{|c|c|c|}
\hline $\begin{array}{l}\text { Jahre unserer } \\
\text { Zeitrechmung }\end{array}$ & $\begin{array}{c}\text { Babylon: Jahresbeginn } \\
\text { am 1. Nisan }\end{array}$ & $\begin{array}{l}\text { Juda: Jahresbeginn } \\
\text { am 1. Tischri }\end{array}$ \\
\hline 610 & \multirow{2}{*}{ 16. Nabopolassar } & 30. Josia \\
\hline \multirow{2}{*}{609} & & 31. Josia \\
\hline & 17. Nabopolassar & \multirow{2}{*}{$\begin{array}{l}\text { Akzessionsjahr Jojakim } \\
\text { oder } 1 \text {. Joahas }\end{array}$} \\
\hline 608 & 18. Nabopolassar & \\
\hline 607 & 19. Nabopolassar & 1. Jojakim \\
\hline 606 & 20. Nabopolassar & 2. Jojakim \\
\hline 605 & \multirow{2}{*}{$\begin{array}{l}\text { 21. Nabopolassar/Antritt } \\
\text { Nebukadnezars }\end{array}$} & 3. Jojakim \\
\hline \multirow{2}{*}{604} & & 4. Jojakim \\
\hline & 1. Nebukadnezar & \multirow{2}{*}{ 5. Jojakim } \\
\hline \multirow[t]{2}{*}{603} & \multirow{2}{*}{ 2. Nebukadnezar } & \\
\hline & & 6. Jojakim \\
\hline 598 & 7. Nebukadnezar & \\
\hline 597 & 8. Nebukadnezar & 11. Jojakim \\
\hline \multirow{2}{*}{596} & \multirow{2}{*}{ 9. Nebukadnezar } & 1. Zedekia \\
\hline & & 2. Zedekia \\
\hline 588 & 17. Nebukadnezar & \\
\hline 587 & $10 \quad 1010$ & 10. Zedekia \\
\hline & 18. Nebukadnezar & 11. Zedekia \\
\hline 586 & 19. Nebukadnezar & \\
\hline 585 & 20. Nebukadnezar & \\
\hline
\end{tabular}


T a b e 11 e II

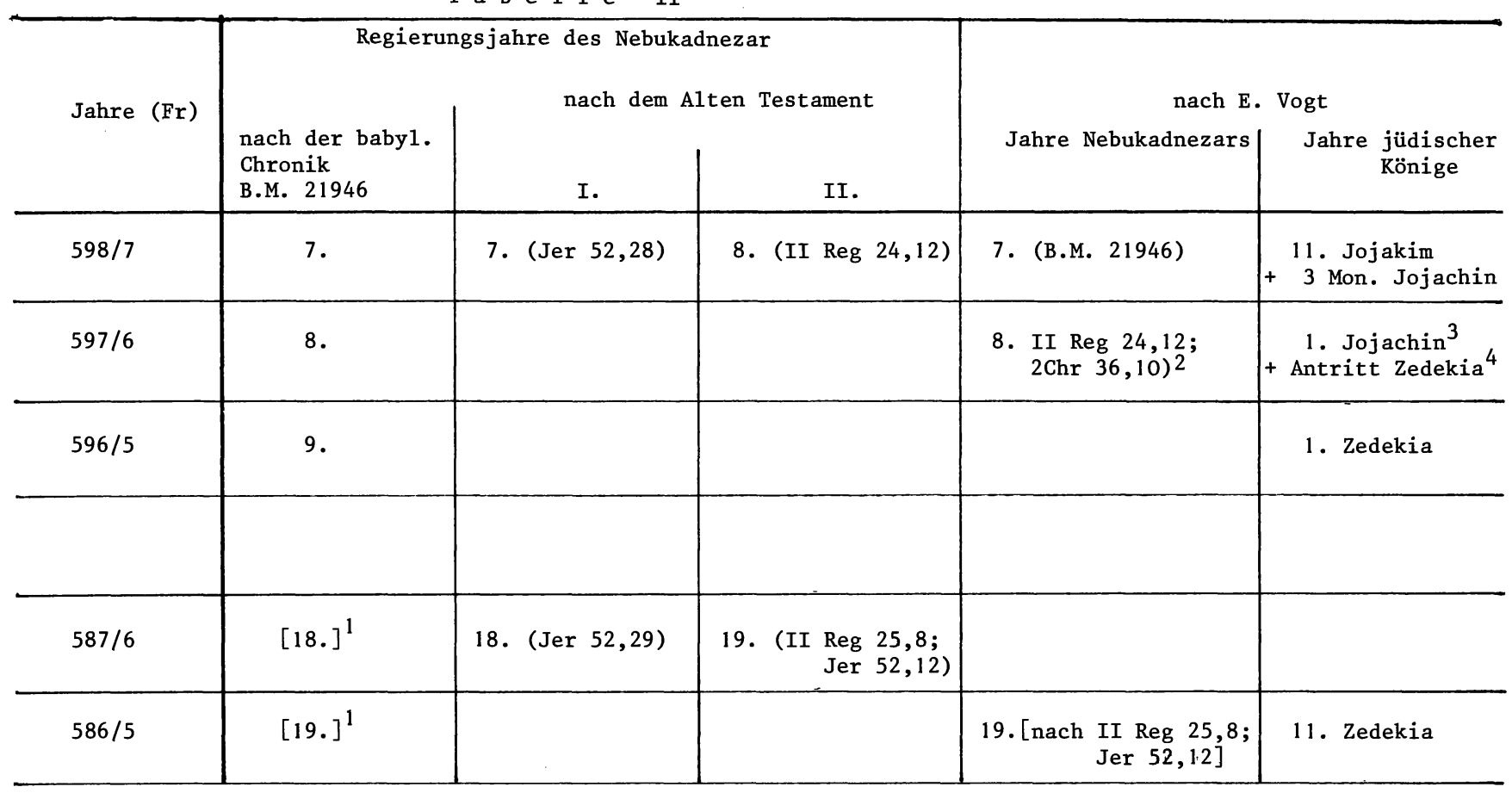

1. Diese Angaben sind (noch) nicht erhalten, sie resultieren aber zwingend aus den vorhergehen-

2. Vogt, Bib1 56, 227.229

3. Vogt, Bib1 56, 228
4. Vogt, VTS 4, 95 Anm. 1 [= Jahr "0" Zedekia], Bib1 56, 228 
T a b e 11 e III

Die verschiedenen Synchronismen

\begin{tabular}{|c|c|c|c|c|c|}
\hline Ereignis & Judäische Könige & $\begin{array}{l}\text { Synchronismen } \\
\text { System I }\end{array}$ & $\begin{array}{l}\text { Babylonische } \\
\text { Chronik }\end{array}$ & Josephus & $\begin{array}{l}\text { Synchronismen } \\
\text { System II }\end{array}$ \\
\hline Wort Jahwes an Jeremia & 4. Jojakim & & & $\begin{array}{c}\text { Antritt Nebukadnezar } \\
\text { ant. } \mathrm{X}, 84\end{array}$ & $\begin{array}{l}\text { 1. Nebukadnezar } \\
\text { Jer } 25,1\end{array}$ \\
\hline $\begin{array}{l}\text { Ägyptisches Heer am } \\
\text { Euphrat }\end{array}$ & 4. Jojakim & & $\begin{array}{l}\text { 21. } \\
\text { Nabopolassar } \\
\text { B.M. 21 } 946 \\
\text { Obv. 1-7 } \\
\text { 1. Elu1 Antritt } \\
\text { Nebukadnezars } \\
\text { ebd. 10-11 }\end{array}$ & & $\begin{array}{l}\text { Nebukadnezar } \\
\text { "König" von Babe1 } \\
\text { Jer } 46,2\end{array}$ \\
\hline $\begin{array}{l}\text { Tribut Jojakims } \\
\text { an Nebukadnezar }\end{array}$ & 8. Jojakim & & & $\begin{array}{l}\text { 4. Nebukadnezar } \\
\text { ant. } \mathrm{X}, 87\end{array}$ & \\
\hline $\begin{array}{l}\text { 1. Eroberung Jerusalems } \\
\text { Gefangennahme Jojakins } \\
\text { Deportation von } \\
3023 \text { Judäern }\end{array}$ & 11. Jojakim & $\begin{array}{l}\text { 7. Nebukadnezar } \\
\text { Jer } 52,28\end{array}$ & $\begin{array}{l}\text { 7. Nebukadnezar } \\
\text { B.M. 21 } 946 \\
\text { Obv. 11-13 }\end{array}$ & & $\begin{array}{l}\text { 8. Nebukadnezar } \\
\text { 2Kön } 24,12\end{array}$ \\
\hline $\begin{array}{l}\text { Wort Jahwes an Jeremia: } \\
\text { Belagerung von } \\
\text { Jerusalem }\end{array}$ & 10. Zedekia & - & & & $\begin{array}{l}\text { 18. Nebukadnezar } \\
\text { Jer } 32,1\end{array}$ \\
\hline $\begin{array}{l}\text { 2. Eroberung Jerusalems } \\
\text { Deportation von } \\
832 \text { Jerusalemern }\end{array}$ & 11. Zedekia & $\begin{array}{l}\text { 18. Nebukadnezar } \\
\text { Jer } 52,29\end{array}$ & & $\begin{array}{l}\text { 18. Nebukadnezar } \\
\text { ant. X, } 146 \\
\text { c. Ap. I, } 154\end{array}$ & $\begin{array}{l}\text { 19. Nebukadnezar } \\
\text { 2Kön } 25,3 f .8 \\
\text { Jer } 52,6 f .12\end{array}$ \\
\hline
\end{tabular}


$\mathrm{T}$ a b e $1: 1$ e IV

\begin{tabular}{|c|c|c|c|c|c|c|}
\hline \multirow{2}{*}{$\begin{array}{l}\text { Jahre unse- } \\
\text { rer Zeit- } \\
\text { rechnung }\end{array}$} & \multicolumn{2}{|c|}{ Malamat } & \multicolumn{2}{|r|}{ Vogt } & \multicolumn{2}{|c|}{ Kutsch } \\
\hline & $\begin{array}{l}\text { Jahre der } \\
\text { Könige } \\
1 . \text { VII. bis } \\
\text { Ende VI. }\end{array}$ & $\begin{array}{l}\text { Jahre der Ver- } \\
\text { bannung } \\
\text { 1.I. bis } \\
\text { Ende XII. }\end{array}$ & $\begin{array}{l}\text { Jahre der } \\
\text { Könige } \\
\text { l.I. bis } \\
\text { Ende XII. }\end{array}$ & $\begin{array}{l}\text { Jahre der Ver- } \\
\text { bannung } \\
\text { l.I. bis } \\
\text { Ende XII. }\end{array}$ & $\begin{array}{l}\text { Jahre der } \\
\text { Könige } \\
\text { 1.I. bis } \\
\text { Ende XII. }\end{array}$ & $\begin{array}{l}\text { Jahre der Ver- } \\
\text { bannung } \\
\text { l.I. bis } \\
\text { Ende XII. }\end{array}$ \\
\hline 598 & \multirow{2}{*}{ 11. Jojaqim } & & 11. Jojaqim & & 11. Jojaqim & 1. Verbannung \\
\hline 597 & & 1. Verbannung & "Antrittsjahr" & 1. Verbannung & 1. Zedekia & 2. Verbannung \\
\hline 596 & 1. Zedekia & 2. Verbannung & 1. Zedekia & 2. Verbannung & 2. Zedekia & 3. Verbannung \\
\hline 595 & \multirow{2}{*}{ 3. Zedekia } & 3. Verbannung & 2. Zedekia & 3. Verbannung & 3. Zedekia & 4. Verbannung \\
\hline 594 & & 4. Verbannung & 3. Zedekia & 4. Verbannung & 4. Zedekia & 5. Verbannung \\
\hline 593 & 4. Zedekia & 5. Verbannung & 4. Zedekia & 5. Verbannung & 5. Zedekia & 6. Verbannung \\
\hline 588 & \multirow{2}{*}{ 10. Zedekia } & & & & 10. Zedekia & 11. Verbannung \\
\hline 587 & & 11. Verbannung & 10. Zedekia & 11. Verbannung & 11. Zedekia & 12. Verbannung \\
\hline 586 & 11. Zedekia & 12. Verbannung & 11. Zedekia & 12. Verbannung & & \\
\hline 585 & & & & & & \\
\hline
\end{tabular}





\section{LITERATURVERZEICHNIS}

ALBRIGHT, W.F., The Nebuchadressar and Neriglissar Chronicles: BASOR 143, 1956, 28-33

ALBRIGHT, W.F., The Seal of Eliakim and the Latest Preëxilic History of Judah: with some Observations on Ezekiel JBL 51, 1932, 77-106

ANDERSEN, K.T., Die Chronologie der Könige von Israel und Juda: StTh 23, 1969, 69-114

BARROIS, A.G., Manuel d'Archéologie Biblique II, Paris 1953

BEGRICH, J., Die Chronologie der Könige von Israel und Juda und die Quellen des Rahmens des Königsbuches (BHTh 3), Tübingen 1929

BERRY, G.R., The Title of Ezekiel (1,1-3): JBL 51, 1932, 54-57

BERTHOLET, A., Das Buch Hesekiel (KHC XII), Freiburg i.B. Leipzig - Tübingen 1897

BERTHOLET, A., Hesekiel. Mit einem Beitrag von K. Galling (HAT I, 13), Tübingen 1936

BEWER, J.A., Beiträge zur Exegese des Buches Ezechiel: ZAW 63, $1951,193-201$

BRIGHT, J., Jeremiah (The Anchor Bible), Garden City, New York 1965

BUDDE, K., Zum Eingang des Buches Ezechiel: JBL 50, 1931,

CLINES, D.J.A., Regnal Year Reckoning in the Last Years of the Kingdom of Judah: Australian Journal of Biblical Archaeology 2, 1972 (erschienen 1973), 9-34

COOKE, G.A., The Book of Ezekiel (ICC), Edinburgh 1936 (= 1951)

COWLEY, A., Aramaic Papyri of the Fifth Century B.C., Oxford 1923

DUHM, B., Das Buch Jeremia (KHC XI), Tübingen - Leipzig 1901

EDZARD, D.O., Sumerische Rechtsurkunden des III. Jahrtausends aus der Zeit vor der III. Dynastie von Ur (ABAW NF 67), München 1968

EICHRODT, W., Der Prophet Hesekiel. Kapitel 1-18 (ATD 22/1), Göttingen 1959

EICHRODT, W., Der Prophet Hesekiel. Kapitel 19-48 (ATD 22/2), Göttingen 1966

EISSFELDT, 0., Das Datum der Belagerung von Tyrus durch Nebukadnezar: FF 9, 1933, 421-422 = DERS., Kleine Schriften II, Tübingen 1963, 1-4

ELLIGER, K., Leviticus (HAT I,4), Tübingen 1966

FINEGAN, J., Handbook of Biblical Chronology, Princeton, New Jersey, 1964 
FLEMING, W.B., The History of Tyre (Columbia University Oriental Studies X), New York 1915 (= 1966)

FOHRER, G., Ezechiel. Mit einem Beitrag von K. Galling (HAT I, 13), Tübingen 1955

FOHRER, G., Die Hauptprobleme des Buches Ezechiel (BZAW 72), Berlin 1952

FREEDY, K.S. - REDFORD, D.B., The Dates in Ezekiel in Relation to Biblical, Babylonian and Egyptian Sources: JAOS $90,1970,462-485$

GADD, C.J., The Fall of Nineveh, London 1923

GALLING, K., Die Bücher der Chronik, Esra, Nehemia (ATD 12), Göttingen 1954

GALLING, K., Die Liste der aus dem Exil Heimgekehrten, in: DERS., Studien zur Geschichte Israels im persischen Zeitalter, Tübingen 1964, 89-108

GALLING, $\mathrm{K}_{\dot{j}_{1979}}(\mathrm{Hg} \cdot)$, Textbuch zur Geschichte Israels, Tübingen

GNILKA, J., Das Evangelium nach Markus. 2. Teilband. Mk 8,27 16,20 (EKK II/2), Zürich - Einsiedeln - Köln und Neukirchen-Vluyn 1979

HERNTRICH, V., Ezechielprobleme (BZAW 61), Gießen 1932

HERRMANN, J., Ezechiel (KAT XI), Leipzig - Erlangen 1924

HERRMANN, $S_{.,}$Geschichte Israels in alttestamentlicher Zeit, München 21980

HOWIE, C.G., The Date and Composition of Ezekiel (JBL Monogr. IV), New Haven, Conn. 1950

HYATT, J.Ph., Jeremiah. Introduction and Exegesis: IB V, New York - Nashville 1956, 775-1142

JEPSEN, A., Zur Chronologie der Könige von Israel und Juda, in: A. JEPSEN - R. HANHART, Untersuchungen zur israelitisch-jüdischen Chronologie (BZAW 88), Berlin 1964, $1-48$

KATZENSTEIN, H.J., The History of Tyre. From the Beginning of the Second Millenium B.C.E. until the Fall of the Neo-Babylonian Empire in 538 B.C.E., Jerusalem 1973

KITTEL, R., Die Bücher der Könige (HK I,5), Göttingen 1900

KOHLER, J. - UNGNAD, A., Hammurabi's Gesetz. Band V: Übersetzte Urkunden, Verwaltungsregister, Inventare, Erläuterungen, Leipzig 1911

KOSCHAKER, P. - UNGNAD A., Hammurabi's Gesetz. Band VI: Übersetzte Urkunden mit Rechtserläuterungen, Leipzig 1923

KRAETZSCHMAR, R., Das Buch Ezechiel (HK III,3), Göttingen 1900

KRAUS, H.J., Gottesdienst in Israel, München ${ }^{2} 1962$

KUHL, C., Die "Wiederaufnahme" - ein literarkritisches Prinzip?; ZAW 64, 1952, 1-11 
KUTSCH, E., Zur Chronologie der letzten judäischen Könige (Josia bis Zedekia): ZAW 71, 1959, 270-274

KUTSCH, E., Das Herbstfest in Israel (Theol. Diss. Mainz 1955)

KUTSCH, E., Das Jahr der Katastrophe: 587 v. Chr.: Bibl 55, $1974,520-545$

KUTSCH, E., "... denn Jahwe vernichtet die Philister". Erwägungen zu Jer 47,1-7, in: Die Botschaft und die Boten. Festschrift für Hans Walter Wolff, Neukirchen-Vluyn $1981,253-267$

KUTSCH, E., Salbung als Rechtsakt im Alten Testament und im Alten Orient (BZAW 87), Berlin 1963

LANG, B., Ezechiel. Der Prophet und das Buch (EdF 153), Darmstadt 1981

LEHMANN, K., Auferweckt am dritten Tag nach der Schrift: QD 38, $1968,262-272$

LESLIE, E.A., Jeremiah. Chronologically arranged, translated and interpreted, New York - Nashville 1954

McArthur, H.K., "On the Third Day": NTS 18, 1971/72, 81-86

MALAMAT, A., The Last Kings of Judah and the Fall of Jerusalem: IEJ $18,1968,137-156$

MALAMAT, A., A New Record of Nebuchadrezzar's Palestinian Campaigns: IEJ $6,1956,246-256$

MALAMAT, A., The Twilight of Judah in the Egyptian-Babylonian Maelstrom: VTS 28, 1975, 123-145

MALAMAT, A., The Last Years of the Kingdom of Judah, = Chapter $\mathrm{X}$ in: The World History of the Jewish People. Vol IV. The Age of Monarchies. 1. Political History, Jerusalem 1979, 205-221.349-353

MEISSNER, B., Babylonien und Assyrien I, Heidelberg 1920

MERX, A., Der Werth der Septuaginta für die Textkritik des Alten Testaments, an Ezechiel aufgezeigt: JpTh 9, 1883, 65-77

PARKER, R.A. - DUBBERSTEIN, W.H., Babylonian Chronology 626 B.C. - A.D. 75 (Brown University Studies XIX), Providence, Rhode Island 1956

PROCKSCH, O., Theologie des Alten Testaments, Gütersloh 1950

ROTHSTEIN, W., Das Buch Jeremia: HSAT I, Tübingen 1922, 720-868

RUDOLPH, W., Jeremia (HAT I,12), Tübingen 31968

SACK, R.H., Amel-Marduk 562-560 B.C. A Study based on Cuneiform, old Testament, Greek, Latin and Rabbinical Sources (AOAT.S 4), Kevelaer - Neukirchen-Vluyn 1972

SAN NICOLO, M. - UNGNAD, A., Neubabylonische Rechts- und Verwaltungsurkunden I, Leipzig 1935 (= 1974)

SELLIN, E., Geschichte des israelitisch-jüdischen Volkes II, Leipzig 1932 
SMEND, R., Der Prophet Ezechiel, Leipzig ${ }^{2} 1880$

SNAITH, N.H., The Dates in 'Ezekiel': ExpT 59, 1947/48, 315-316

SNAITH, N.H., The Jewish New Year Festival, London 1947

TADMOR, H., The Chronology of the First Temple Period. A Presentation and Evaluation of the Sources, = Chapter III in: The World History of the Jewish People. Vol IV. The Age of Monarchies. 1. Political History, Jerusalem 1979, 44-60.318-320

TAYLOR, S.G., A Reconsideration of the 'Thirtieth Year' in Ezekiel 1,1: Tyndale Bulletin 17, 1966, 119-120

THIEL, W., Die deuteronomistische Redaktion von Jeremia 1-25 (WMANT 41), Neukirchen-VIuyn 1973

THIEL, W., Die deuteronomistische Redaktion von Jeremia 26-45 (WMANT 52), Neukirchen-Vluyn 1981

THIELE, E.R., The Mysterious Numbers of the Hebrew Kings. A Reconstruction of the Chronology of the Kingdoms of Israel and Judah, Chicago 1951

TUR-Sinai, N.H., The Double Dating of Ezekiel i,1-3: BIES 23, $1959,5-7.110$

UNGER, E., Nebukadnezar II. und sein Šandabakku (Oberkommissar) in Tyrus: ZAW 44, 1926, 314-317

VOGT, E., Bemerkungen über das Jahr der Eroberung Jerusalems: Bibl 56, 1975, 223-230

VOGT, E., Die neubabylonische Chronik über die Schlacht bei Karkemisch und die Einnahme von Jerusalem: VTS 4, 1957, 67-96

VOLZ, P., Der Prophet Jeremia (KAT X), Leipzig - Erlangen ${ }^{2} 1928$

WEISBERG, D.B., Guild Structure and Political Allegiance in Early Achaemenid Mesopotamia (Yale Near Eastern Researches 1), New Haven - London 1967

WEISER, A., Der Prophet Jeremia. Kapitel 25,15-52,34 (ATD 21), Göttingen 1955

WHITLEY, C.F., The 'Thirtieth' Year in Ezekiel i 1: VT 9, 1959, $326-330$

WISEMAN, D.J., Chronicles of Chaldaean Kings (626-556 B.C.) in the British Museum, London 1956

ZIMMERLI, W., Ezechiel. 2 Bände (BK XIII/1+2), Neukirchen-Vluyn 21979 


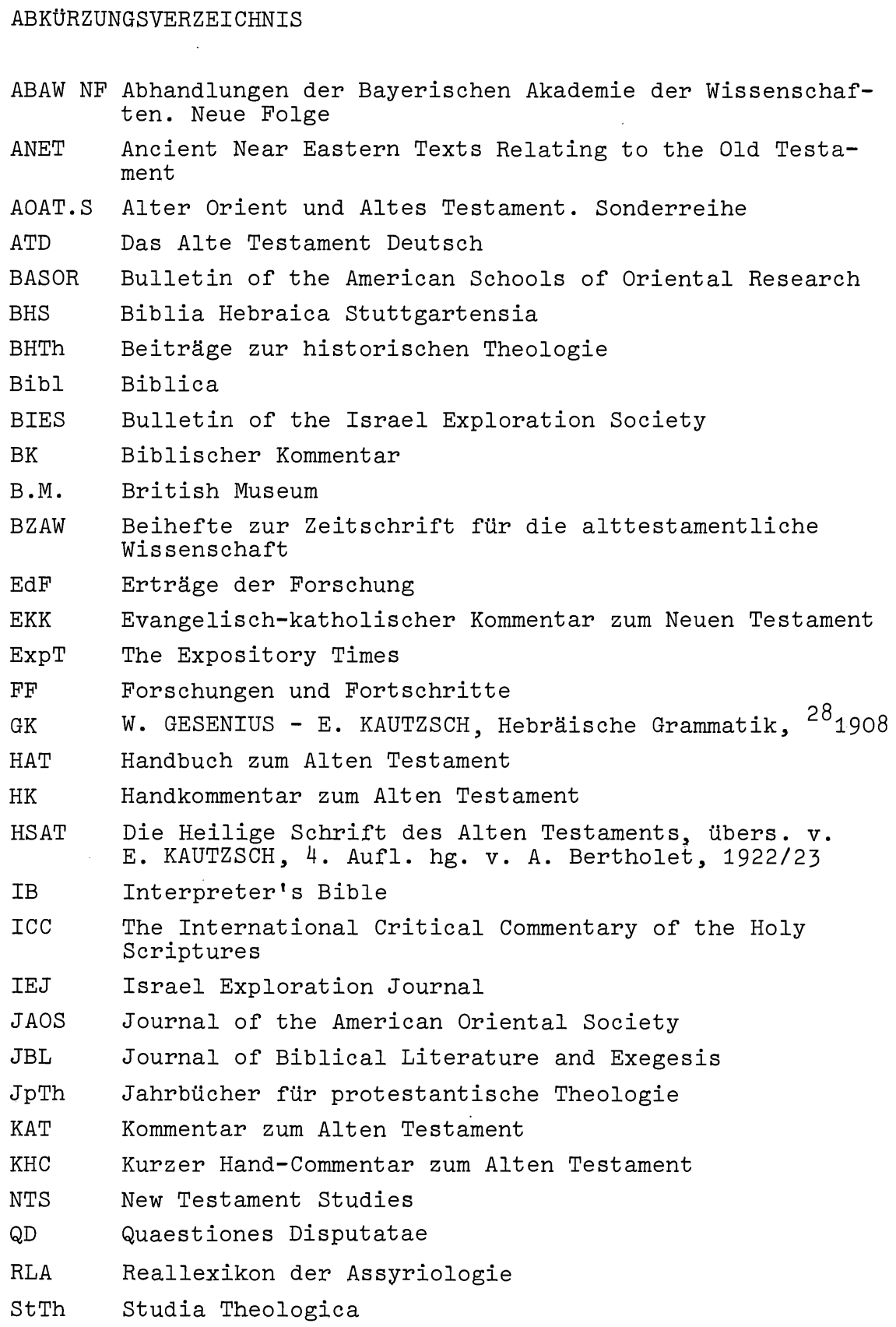


VT Vetus Testamentum

VTS Vetus Testamentum Supplementum

WMANT Wissenschaftliche Monographien zum Alten und Neuen Testament

ZAW Zeitschrift für die alttestamentliche Wissenschaft 